\title{
Experimental Investigation of Using Sandwich Panels as Infill Plate in a Steel Plate Shear Wall
}

\author{
Said DUSAK ${ }^{1}$ \\ Cem YALÇIN ${ }^{2}$ \\ Ahmet Necati YELGIN ${ }^{3}$
}

\begin{abstract}
A total of five steel frame specimens, one bare and four infilled, were designed with thinwalled steel sheets and corrugated sandwich infill panels in order to increase their load and energy dissipation capacity. For this experimental study, single-story, single-bay steel frames of nominally-pinned beam-to-column connections were prepared with a scale ratio of 1:3. A quasi-static cyclic loading pattern was applied to the control bare and infilled steel frames, and their behavior was investigated both experimentally and analytically using SAP2000 and ABAQUS finite element software. First, five identical bare steel frame specimens were prepared and one of them was tested as a control specimen, and its rigidity and cyclic behavior was determined experimentally. Then, two sandwich panel specimens were prepared by connecting sandwich panels in the second and third bare steel frames using appropriate connections. The fourth specimen had only a single steel plate infill. Finally, the fifth specimen was prepared by removing the polyurethane material from inside the sandwich panel and only steel plates were attached to both faces of the frame. This way, it was possible to compare the effect of the polyurethane material inside the sandwich panel and the corrugated steel plate on the overall system behavior. In all specimens, the infill plates were fastened to the frame connection profiles using self-drilling screws and the responses of the specimens were compared in terms of their maximum load capacity, initial stiffness, ductility and energy dissipation capacity values under cyclic loading. The experimental and analytical investigations showed that, similarly to steel plate infills, the specimens with sandwich panels also behaved in a ductile manner with relatively lower load and energy dissipation capacities. Results of the strip model and the finite element model analyses were then compared with the experimental results and they were both found to be in good agreement.
\end{abstract}

Keywords: Steel plate shear wall, infill steel frame, sandwich panel, composite panel shear wall, cyclic loading, energy dissipation.

Note:

- This paper has been received on April 29, 2019 and accepted for publication by the Editorial Board on September 18, 2019.

- Discussions on this paper will be accepted by January 31, 2021.

- https://dx.doi.org/10.18400/tekderg.559036

1 Sakarya University, Institute of Natural Sciences, Sakarya, Turkey - sdusak@gmail.com https://orcid.org/0000-0002-6903-1695

2 Bogazici University, Department of Civil Engineering, Istanbul, Turkey -yalcince@boun.edu.tr https://orcid.org/0000-0003-3142-8125

3 Sakarya University, Department of Civil Engineering, Sakarya, Turkey - ayelgin@sakarya.edu.tr https://orcid.org/0000-0002-1879-1459 


\section{INTRODUCTION}

Steel plate shear walls have been the subject of many analytical and experimental studies over the past years [1-3], while many of these studies developed models with single infill plates $[4,5]$. In order to increase the energy dissipation capacity of steel frames subjected to lateral loads, steel plate shear walls were constructed by attaching infill panels with different geometric and material properties inside the steel frame, directly or through the use of fish plates [6]. The first studies involved design of plates that were thick enough to withstand shear strength [7]. Later, studies were conducted with out-of-plane buckling of plates under lateral loadings in the form of tension strips to transfer the shear loads. Thus, thinner plates started to be used and they were allowed to buckle. A theoretical strip model was developed, defining the formation of tensile fields as plates buckle prior to yielding, while continuing to transfer lateral loads $[8,9]$. Many studies have been conducted in the placement of thin vs. thick infill plates inside steel plate shear walls $[10,11]$, the addition of stiffeners to the steel plate [12], the use of different types of frame connections [13,14], the differences in material characteristics and yield strengths [15], the introduction of perforations of different forms to certain areas on the plate so that it could absorb more energy [16], the use of corrugated steel infill plates [17], adding steel plate shear walls inside reinforced concrete and composite frames [18, 19], comparing behavior of braced frames and steel plate shear walls [20], and turning steel plates into composite panels with the addition of reinforced concrete partitions [21]. In addition, numerical and experimental studies have been conducted to rigid, semirigid and pinned beam-to-column connection designs [22, 23]. There have also been studies in which the infill plates were connected to the frame elements via beams and columns, or via beams only [24]. These studies demonstrated that different steel plate shear walls increased ductile behavior, energy dissipation capacity, maximum load capacity and the initial stiffness of steel plate shear walls. Berman and Bruneau [25] reported that the addition of steel plates to frames increased the energy dissipation capacity and ductility, and also provided additional shear strength.

\section{OBJECTIVE AND RESEARCH RATIONALE}

The present study aims to transform partition walls into steel plate shear walls without the need for an additional lateral load-resisting system. The objective is to propose an appropriate design to connect sandwich panel partition walls mounted in existing steel frames, thus providing a supplementary lateral load resisting system and strength to existing buildings. Single-story, single-bay specimens with dimensions having approximately a ratio of $1: 3$, when compared to a typical full-scale building frame, were prepared for the present study by connecting various types of infill panels to the frame's beams and columns, representing an intermediate floor of a multi-story building. In addition to the bare frame, three types of infill panels were designed with two sandwich panel specimens and one specimen with single plate of matching thickness, while the other one had steel plates on both sides of the sandwich panel without the polyurethane material. The behaviors of these specimens under cyclic loading were examined experimentally and analytically, and the results were compared in terms of initial stiffness, ductility and maximum load and energy dissipation capacity. 


\section{DESIGN OF SPECIMENS AND TEST SETUP}

A single-story, single-bay, steel frame with a nominally-pinned beam-to-column connection, was used as a control bare frame (BF) specimen. The SP1 and SP2 specimens were prepared using sandwich panels as infill plates in the frame. The CLA specimen was prepared by removing the polyurethane material inside the sandwich panel. Finally, the TL specimen was prepared using a single steel plate with matching CLA's plate thickness. The steel frames of the control specimen BF and other specimens had the same characteristics such as dimensions, connection types, cross-sections and materials with the exception of the plates or panels placed inside the frame. Their physical and technical characteristics are presented in Table 1, where " $t$ " represents the plate thickness. To investigate the effect of infill plates, cross-sections were selected so that the plasticization of frame elements before reaching yield values would be prevented. HEA 260 cross-sections were used for the frame columns and HEA 240 cross-sections for the beams. Specimens SP1, SP2, CLA and TL had similar frontal views, as shown in Figure 1, but had different cross-sections, as shown in Figure 2.

Table 1 - Specimen Properties

\begin{tabular}{llll}
\hline $\begin{array}{l}\text { Specimen } \\
\text { No. }\end{array}$ & Specimen Name & $\begin{array}{l}\text { Panel/Plate } \\
\text { Thickness }\end{array}$ & Infill Property \\
\hline 1 & Bare Frame (BF) & \multicolumn{1}{c}{-} & \multicolumn{1}{c}{-} \\
& Sandwich Panel & $t=100 \mathrm{~mm} /$ & $0.5 \mathrm{~mm}$ Steel Plate + \\
2 and 5 & (SP1/SP2) & $0.5 \mathrm{~mm}+0.5 \mathrm{~mm}$ & $\begin{array}{l}99 \mathrm{~mm} \text { Polyurethane }+ \\
0.5 \mathrm{~mm} \text { Steel Plate }\end{array}$ \\
& Two-Faced Discrete & $t=0.5 \mathrm{~mm}+0.5 \mathrm{~mm}$ & $\begin{array}{l}0.5 \mathrm{~mm} \text { Steel Plate }+ \\
99 \mathrm{~mm} \text { Gap }+\end{array}$ \\
3 & Steel Plate(CLA) & & $0.5 \mathrm{~mm}$ Steel Plate \\
& Single Steel Plate (TL) & $t=1.0 \mathrm{~mm}$ & $1.0 \mathrm{~mm}$ Steel Plate \\
\hline
\end{tabular}

In order to minimize the contribution of the infill plates to the frame as much as possible, a nominally-pinned beam-to-column connection was designed. Since all frame specimens are identical, their rigidity would have equal contribution to all infilled specimens, Thus, the augmented capacities of infilled frames could easily be compared with each other, including the control bare frame specimen. Figure 3 provides details of the beam-to-column connections, where the beams are connected to the columns with six M16 bolts, via double angles from the beam web only. The maximum moment capacity of the joint region and the corresponding maximum shear stress acting on each bolt were calculated, and accordingly, six 10.9 class bolts were selected to join beam web to double angles. Especially, this type of connection having a relatively low moment capacity was selected to connect beam and column elements with these bolts in order to make sure that the beam-to-column connection acts as a nominally-pinned joint. 


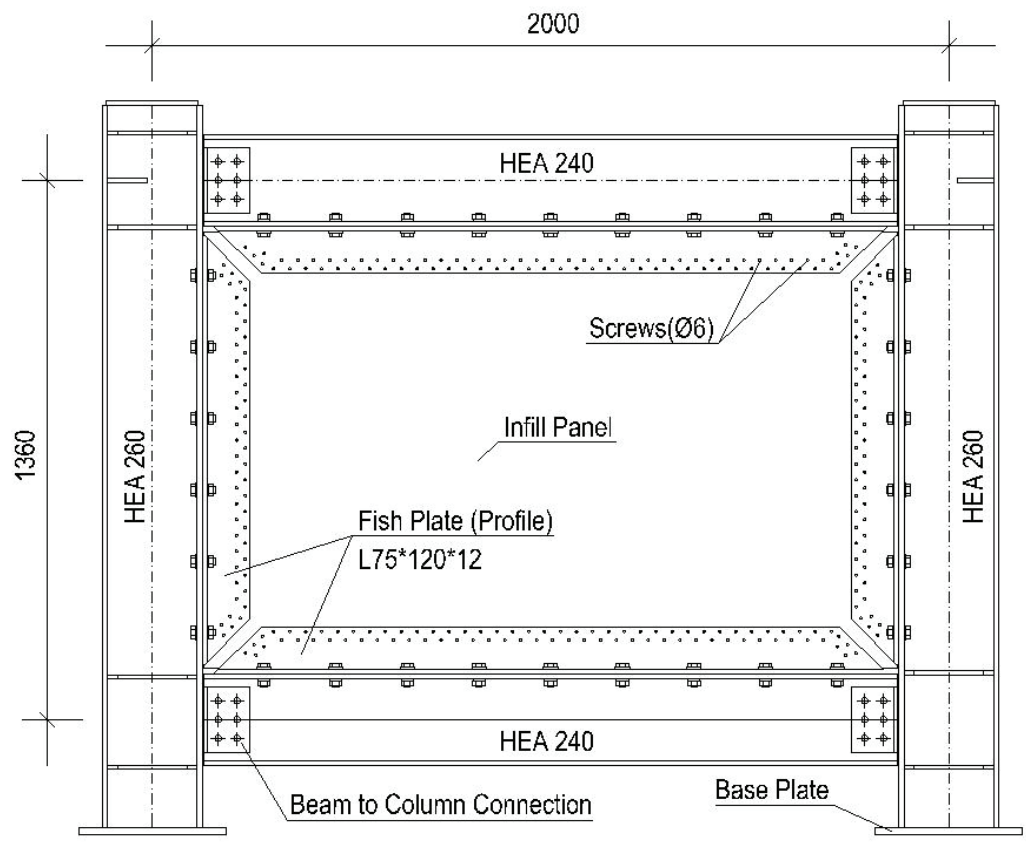

Figure 1 - Details of specimen SP1, SP2, CLA and TL (all dimensions are in mm)

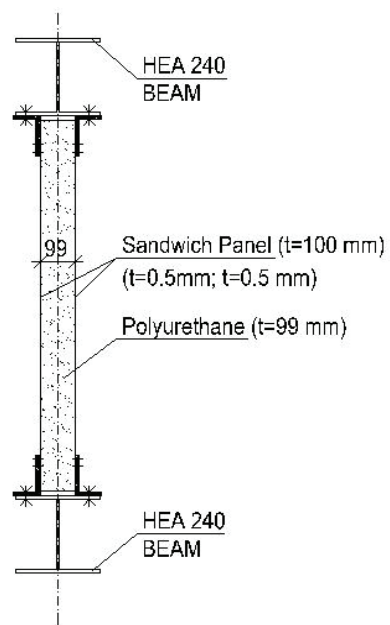

SPECIMEN SP1/ SP2

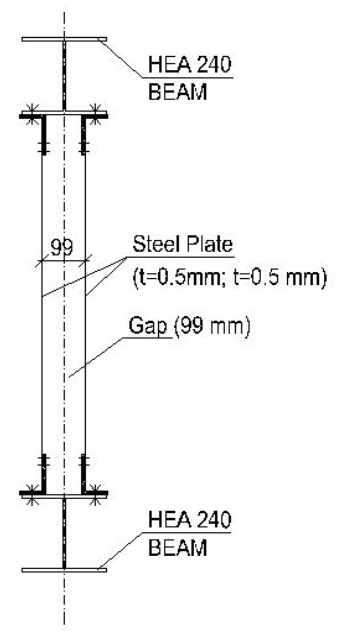

SPECIMEN CLA

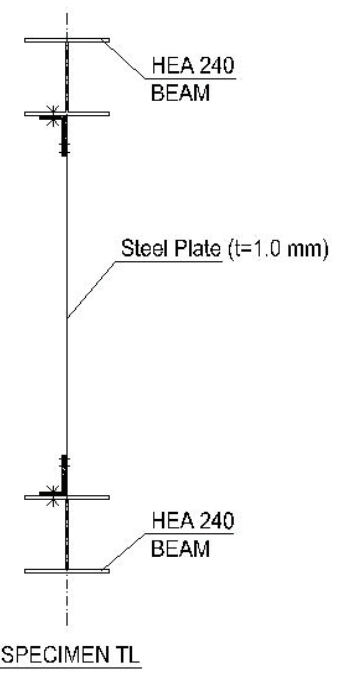

SPECIMEN TL

Figure 2 - Sections of infill panel/plate of each specimen 

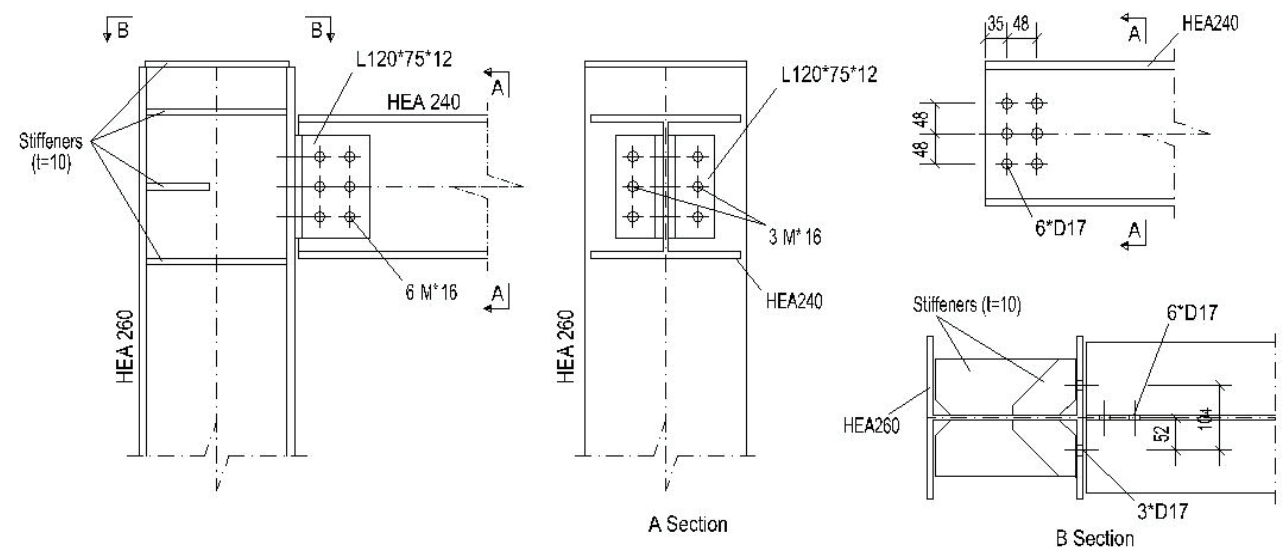

Figure 3 - Beam-to-column connection detail of frame (all dimensions are in mm)

The plates, on the other hand, were connected to the frame via a structural angle section attached to the frame, using self-drilling screws. In the literature, plates were usually connected via a fish plate welded to the frame, whereas in the present study, the connections were prepared with M16 bolts at 180mm center-to-center spacing along the short edge of the L120x75×12 structural steel angle. The connections were located along two lines for the twoface specimens of SP1, SP2 and CLA, and along a single line in the TL specimen, as shown in Figure 4. This connection type would allow easy replacement of plates when there is a need for change of any infill panel at extreme deformations via only the connection bolts. As welded connections may result in local heat-related deformations in thin plates, and because they do not require the preparation of holes prior to connection, the use of self-drilling screws was preferred. This fact was also mentioned by Vatansever and Yardimci [24] as an alternative method of connection. Also, an analytical model for screw connections is developed by Vatansever and Berman [26] as well. The aforementioned study reports that plate-to-frame connections made with self-drilling screws provided sufficient performance [23]. For that reason, 6-mm-diameter self-drilling screws having $310 \mathrm{MPa}$ of yield capacity were preferred in this study. A total of 300 of these screws were used at two rows staggered with $40 \mathrm{~mm}$ centers in order to achieve a uniform load distribution, as shown in Figure 4. The infill plate connection design was carried out according to maximum expected tensile force acting on the strip model. Self-drilling screw diameter and its tensile capacity were calculated prior to the experiment.

Clevises were used to connect the test specimens to the plates, which in turn were fastened to the reinforced concrete foundation with anchors. The reinforced concrete foundation was fixed to the laboratory's strong floor with twelve 50-mm-diameter anchor bolts. The laboratory had a reaction wall with a capacity of $2000 \mathrm{kN}$ and an actuator with a capacity of $1000 \mathrm{kN}$. The attachment holes in the reaction wall at $300 \mathrm{~mm}$ centers played a key role in determining the size of the specimens. Figure 5 shows the experimental setup, while Figure 6 shows the steel plate shear wall specimens with sandwich panel and single steel plate. 

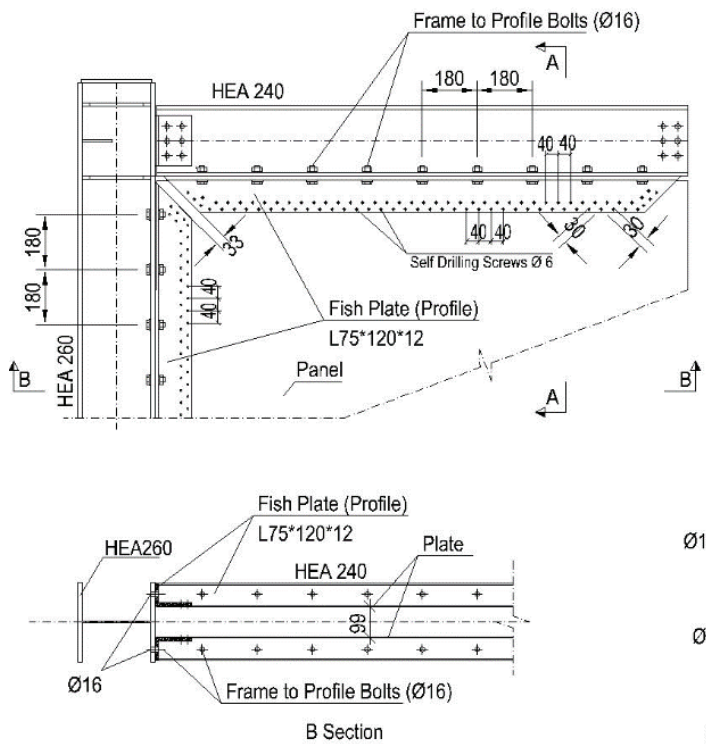

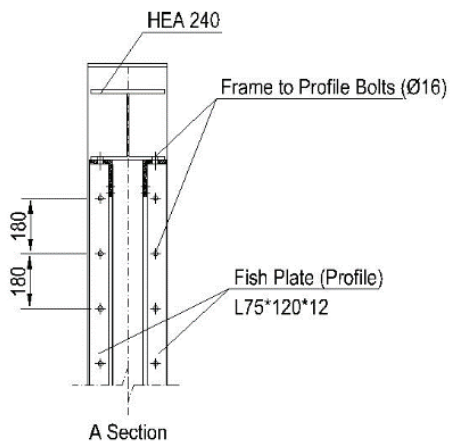

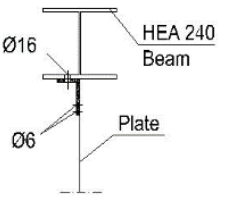

Single Plate

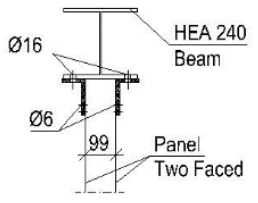

Two Faced Panel

Figure 4 - Infill plate/panel to frame connection detail (all dimensions are in $\mathrm{mm}$ )

To prevent out-of-plane deformations during testing, four lateral bracings with steel rollers at the ends of the front and rear faces were used, aligned with the central axis of the upper beam. Friction was minimized by cleaning the rough surface of the beam, applying grease and attaching rollers to provide free movement along the direction of loading.

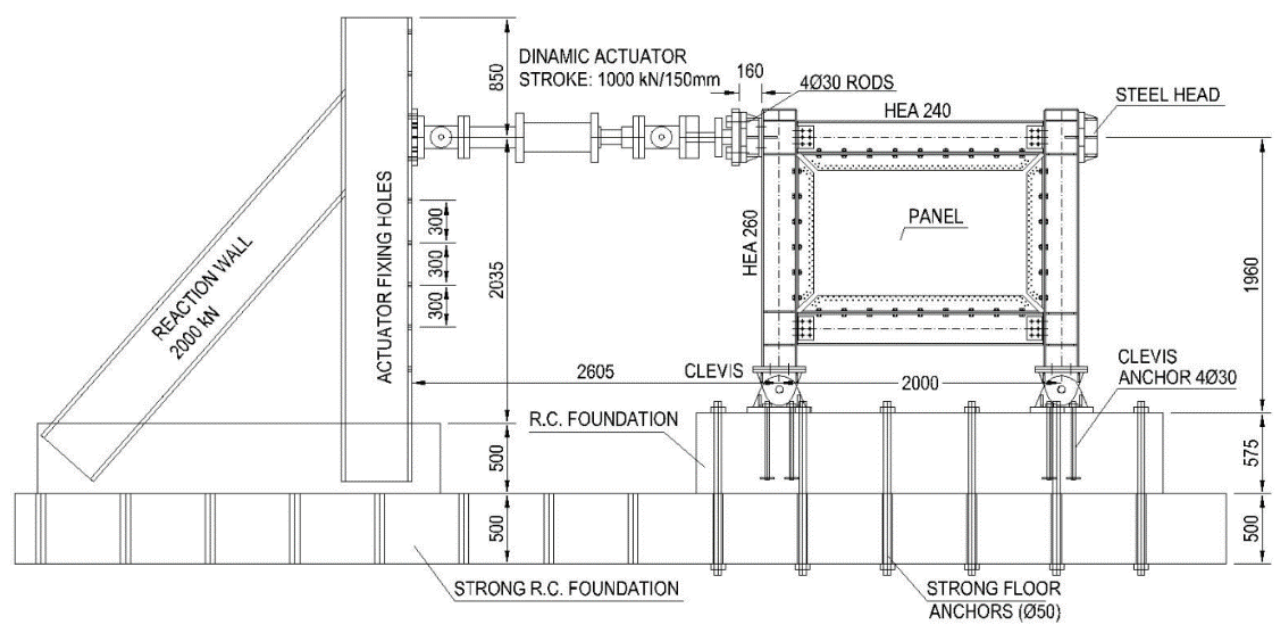

Figure 5 - Test Setup (all dimensions are in $\mathrm{mm}$ ) 


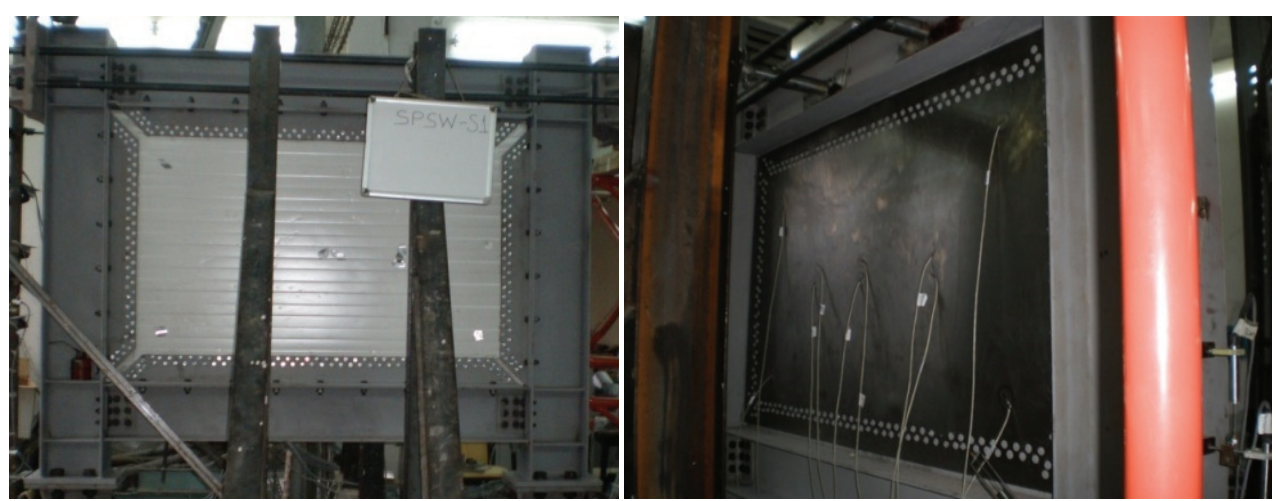

Figure 6 - Sandwich panel shear wall (SP1) and steel plate shear wall (TL) specimens

\section{MATERIAL TEST RESULTS}

Tension tests were conducted on coupons taken from the infill plates of the specimens. Their results are shown in Tables 2 and 3. The cross-section of the sandwich panel used as the infill plate is shown in Figure 7. A steel grade of S275 was used for the frame profiles; S235 grade steel was used for connection plates, infill plates and sandwich panel's steel plates; and grade 10.9 was used for the frame connection bolts. The material characteristics obtained during the coupon test were used in the preparation of the computer models.

Table 2 - Sandwich panel steel plate coupon test results

\begin{tabular}{lccccc}
\hline Specimen No. & $\mathbf{1}$ & $\mathbf{2}$ & $\mathbf{3}$ & Mean & Standard Deviation \\
\hline Thickness $(\mathrm{mm})$ & 0.50 & 0.50 & 0.50 & & - \\
Width $(\mathrm{mm})$ & 25.00 & 25.00 & 25.00 & & \\
Yield Stress $(\mathrm{MPa})$ & 369 & 334 & 290 & 331.0 & 39.3 \\
Ultimate Stress $(\mathrm{MPa})$ & 416 & 373 & 416 & 401.6 & 24.9 \\
\hline
\end{tabular}

Table 3 - Single steel plate coupon test results

\begin{tabular}{lccccc}
\hline Specimen No. & $\mathbf{4}$ & $\mathbf{5}$ & $\mathbf{6}$ & Mean & Standard Deviation \\
\hline Thickness $(\mathrm{mm})$ & 1.00 & 1.00 & 1.00 & & \\
Width $(\mathrm{mm})$ & 25.00 & 25.00 & 25.00 & & \\
Yield Stress $(\mathrm{MPa})$ & 349 & 302 & 349 & 333.5 & 27.2 \\
Ultimate Stress $(\mathrm{MPa})$ & 392 & 430 & 408 & 410.1 & 18.7 \\
\hline
\end{tabular}




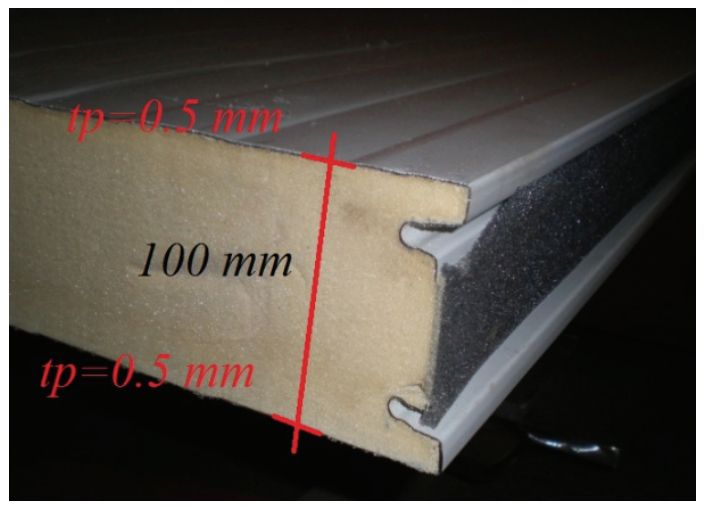

Figure 7 - Sandwich Panel Section

\section{ANALYTICAL MODELING}

Finite element models of the specimens were prepared using the ABAQUS standard software package [27], and the strip model was prepared using SAP2000 structural analysis software [28]. As the strip model turns into diagonal strips and transfers the load when a lateral load is applied along the plane of each plate, these strips were defined as pin-ended members that could only bear axial tension loads. The angles of inclination of the plates were calculated using the method given in Equation 1, with the plates being defined and analyzed as strip members with an inclination of $46^{\circ}$ [8]. The cross-section of each tension strip was defined to be equal to the plate thickness multiplied by the width of the tension field. The computer models were prepared to identify the material qualities and cross-sections of the specimens prior to the experiments, and the obtained experimental results were used to confirm the computer models.

$\tan ^{4} \alpha=\frac{1+\frac{t_{p} L}{2 A_{c}}}{1+t_{p} h\left(\frac{1}{A_{b}}+\frac{h^{3}}{360 I_{c} L}\right)}$

$\alpha \quad$ : Strip inclination angle

$t_{p} \quad$ : Plate thickness

$L \quad$ : Specimen width

$A_{c} \quad$ : Column section area

$h \quad:$ Specimen height

$A_{b} \quad$ : Beam section area

$I_{c} \quad$ : Column inertia moment

The beam-to-column connection of the bare frame was defined in the strip model and also in the finite element model, where the model parameters were calibrated based on test results. In ABAQUS modeling, structural angles in beam-to-column connections were also modeled 
using shell elements and the bolts were defined as fastener elements. At their joining grid, 3 displacement degrees of freedom were defined. In the SAP2000 model, beam-to-column connection regions were modelled according to selected connection type where rotation capacities were calculated from moment capacities and they were defined at the beam end regions. Finally, for the nominally-pinned connection region of the angles, where beams and column elements are connected, their yielding moment capacity was calculated. This value was observed to be around $2.5 \%$ of the plastic moment capacity of the beam. The steel plate and sandwich panel shear wall specimens were modeled with the addition of the infill plates. Although the presence of the polyurethane material was not taken into account in the modeling process, the difference in terms of initial stiffness between model and test results clearly showed the contribution of polyurethane material. A total of 11 parallel tension strips were defined in the strip model, with tensile fields measuring $200 \mathrm{~mm}$ wide, as shown in Figure 8. The graphs obtained following the analysis of the strip model for the steel plate shear wall and the analysis of the bare frame are given in Figure 9. With regards to the frame elements in the finite element model, an S4R shell element was used to define the thin and thick plates, and an S8R5 shell element was used to define thin plates only. The SP1, SP2 and CLA specimens were defined as two-faced $0.5 \mathrm{~mm}$ steel plates, with $100 \mathrm{~mm}$ of gap in between. The coupon test material parameters were used in modeling. The first buckling mode obtained via analysis of the finite element model, which is given in Figure 10, and the buckling mode of the same specimen with $+1 \delta_{y}$ displacement during the experiment is given in Figure 11.

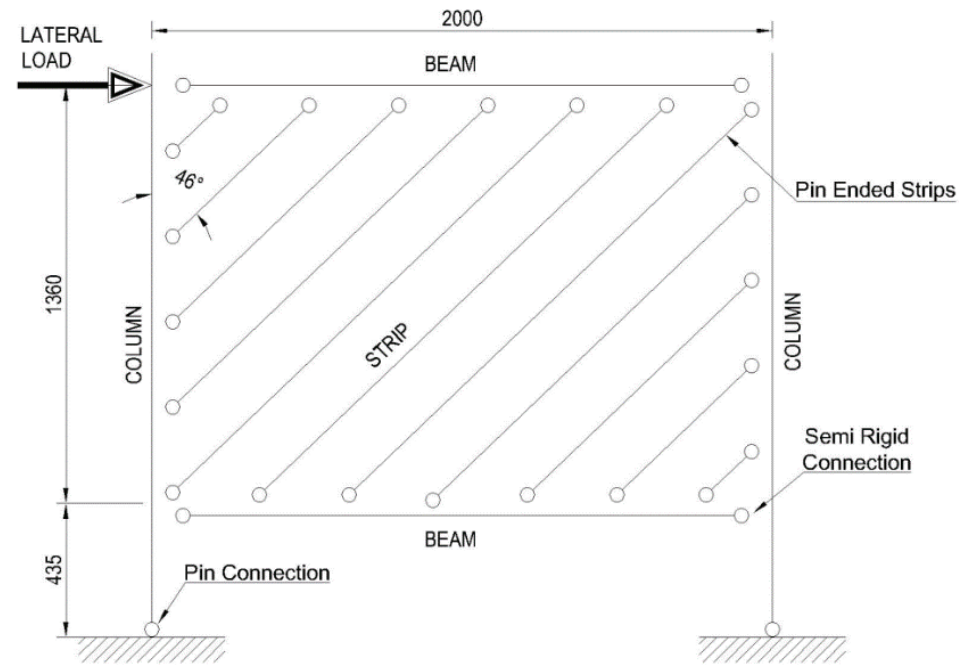

Figure 8 - Strip model of Specimens (all dimensions are in $\mathrm{mm}$ )

After the third cycle, the load was observed to decrease with the crushing of the holes within the web region of the beam in the beam-to-column connections. At the stage where yielding of the connections have started after $0.68 \%$ drift, the loads continued to increase steadily due to contact of the lower and upper flanges of the beams to the adjoining columns. The model, on the other hand, also predicted a rapid increase in loading as the gap in between is defined on the basis of the size of the experimental specimen. 
Experimental Investigation of Using Sandwich Panels as Infill Plate in a Steel ...

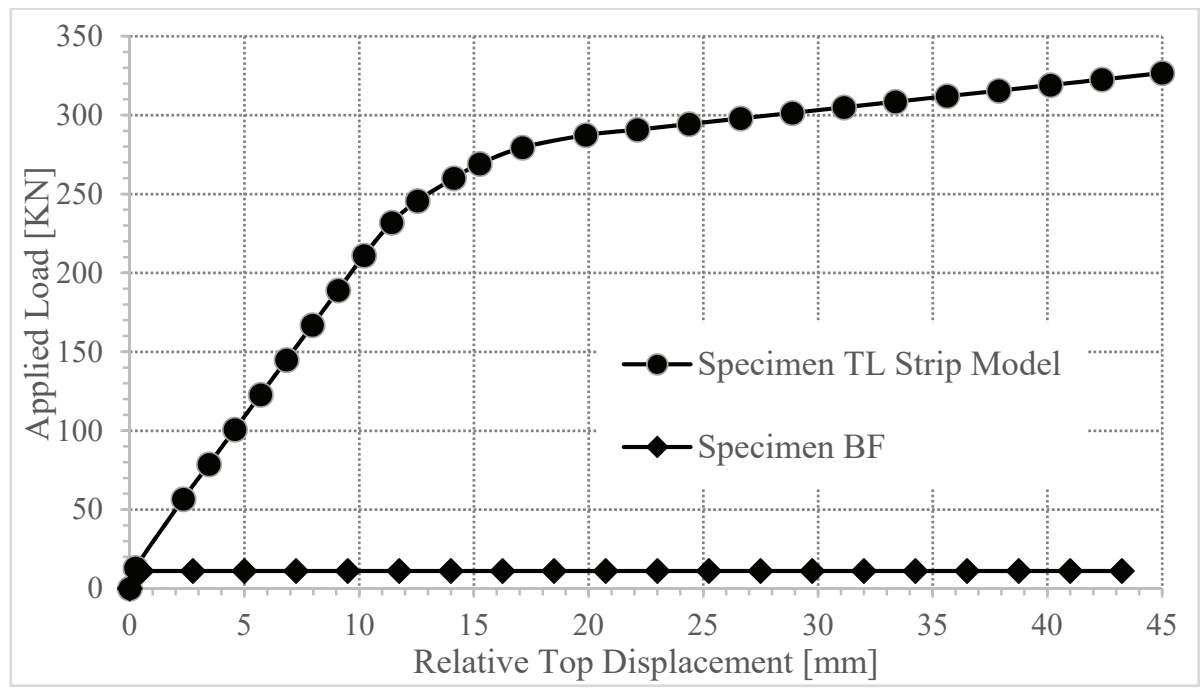

Figure 9 - Steel plate shear wall's strip model and bare frame load displacement curves

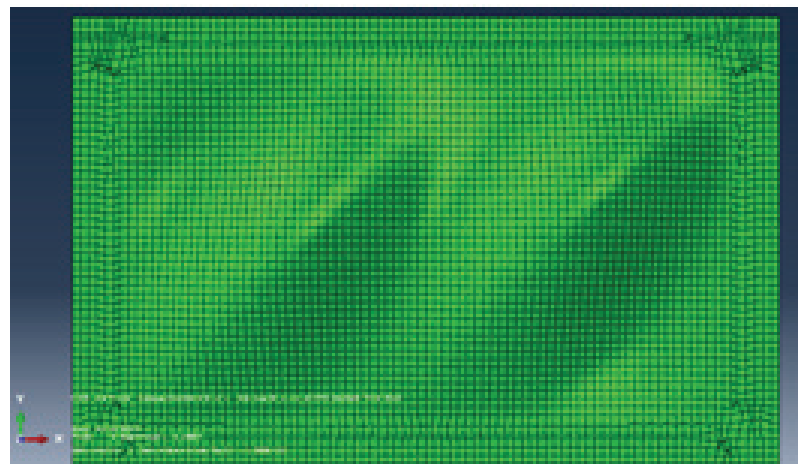

Figure 10 - Finite element model infill plate 1st mode shape

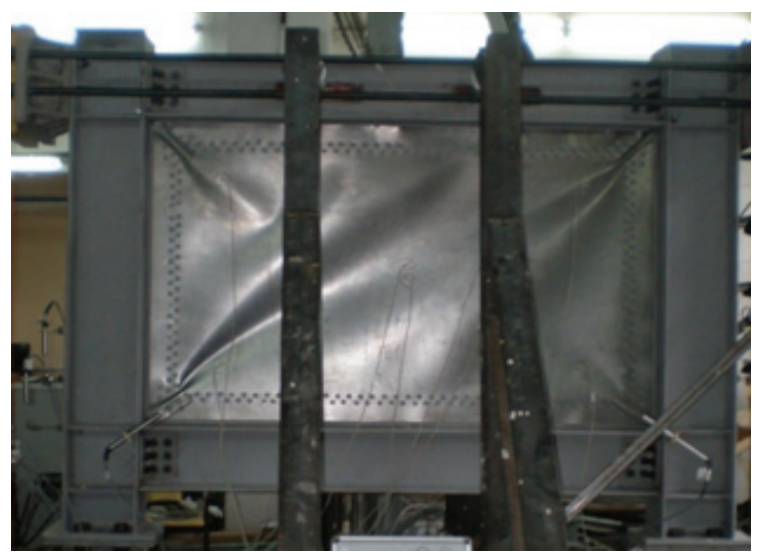

Figure 11 - Specimen TL infill plate at $1 \delta_{y}$ displacement mode shape 
The load displacement curves for the bare frame, obtained from experimental loading and FEM analysis are shown in Figure 12. Bare frame models were calibrated using experimental results, and the modeling of the sandwich panel and steel plate shear wall specimens were completed. In ABAQUS, the structural system, including all connections, were modeled using shell elements. Since bolt holes were not defined in the overall model, the section at these regions were reduced to simulate the real sectional dimensions. In the SAP2000 model, the lateral load levels on the bare frame were checked against the experimental results and it was made sure that the surrounding frame system was modelled correctly. Then, according to rotation values obtained at the joint regions, the strip model was prepared. The loaddisplacement curves obtained FEM analysis are given in Figure 13. The behavior of the specimen that represented the plates on either side of the sandwich panel was very similar to the behavior of the steel plate shear wall specimen.

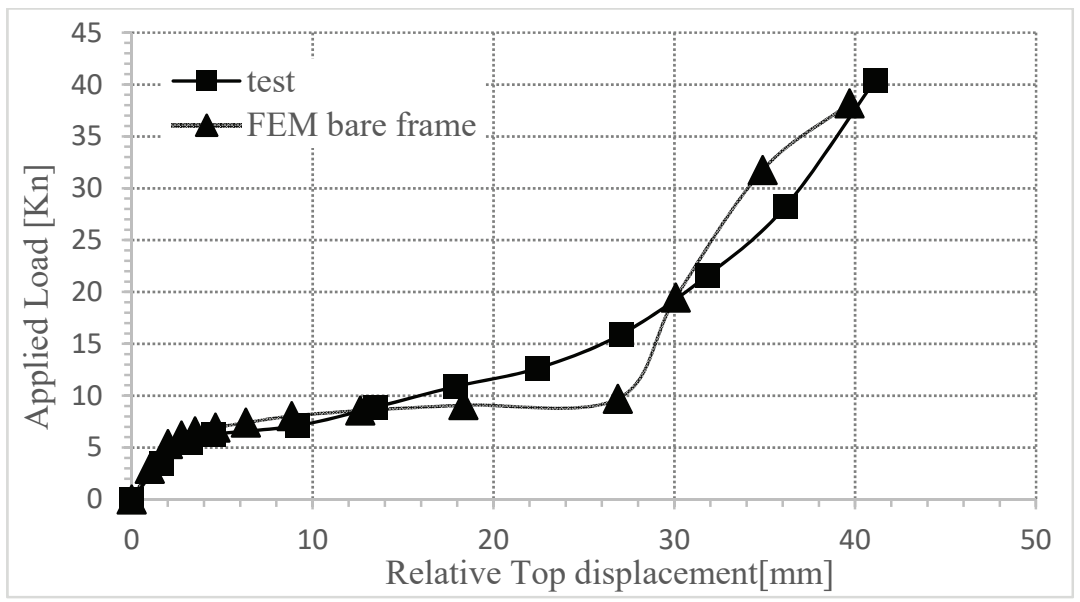

Figure 12 - Bare frame $(B F)$ experimental and finite element analysis load displacement curves

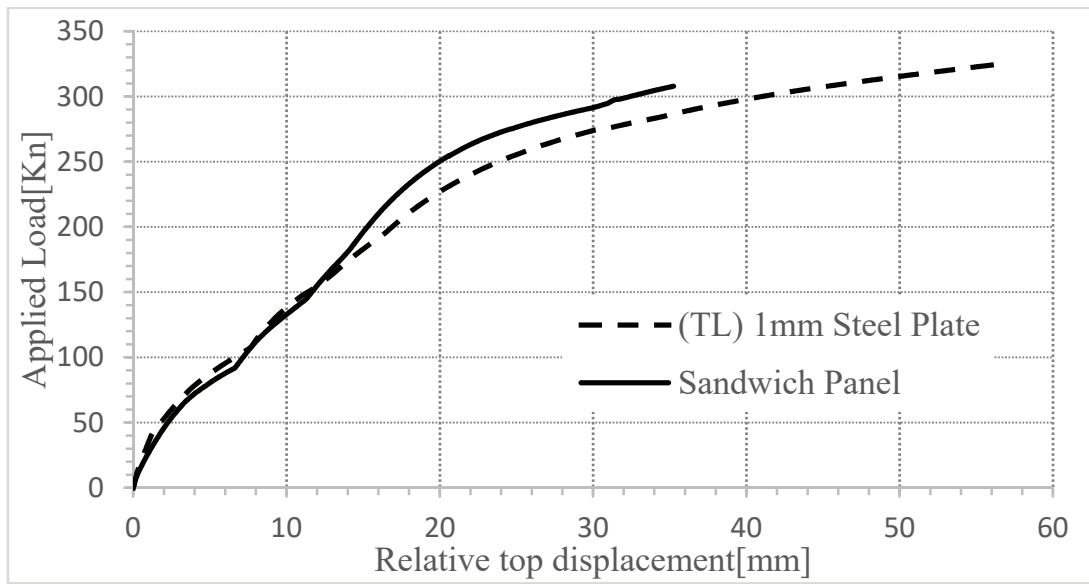

Figure 13 - Steel plate (TL) and sandwich panel shear wall (SP1/SP2) finite element model analysis load displacement curves 


\section{EXPERIMENTAL RESULTS}

The experimental results are presented herein with a discussion of the observations made during the experiments and the obtained data. Quasi-static cyclic loading was applied as per the ATC-24 [29] specifications via $1000 \mathrm{kN}$ actuator with a stroke capacity of $150 \mathrm{~mm}$ push and pull directions. Displacement transducers were placed on the axis of the frame's upper beam, and at the points shown in Figure 14, so that displacements could be measured from desired points for all specimens.

Strain-gauges were mounted at critical sections so that yielding of plates could be monitored. For each plate, 10 strain gauges of 3\% elongation capacity were used as shown in Figure 14. Unlike the plates, beams and columns elements were observed to be within the elastic range, as expected. At maximum load levels, strain values ranged between 0.0040 and 0.0080 , where yielding started around at a strain level of 0.0015 .

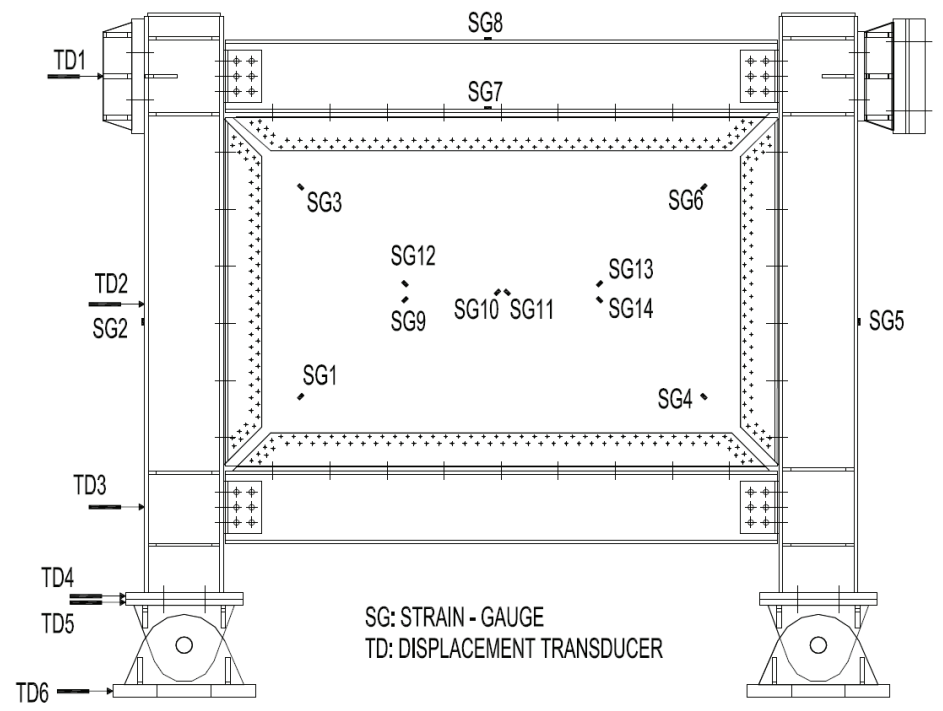

Figure14 - Displacement transducers and strain-gauges arrangement

The displacement transducers placed on beam axes made it possible to determine the storey drifts. A displacement-controlled load was applied prior to and after yielding of the test specimen. The displacement value that corresponding to $Q_{y}$, the yielding load of the system, was denoted as $\delta_{y}$. The cyclic loading steps were increased in multiples of $\delta_{y} .1 / 3$ of the $\delta_{y}$ was applied in the first step, $2 / 3$ of the $\delta_{y}$ was applied in the second step, one $\delta_{y}$ was applied in the third step, and after that, load increased in multiples of $\delta_{y}$. A total of three cyclic loadings were applied per displacement step, and one cyclic loading for the bare frame. According to the loading protocol, corresponding yield displacements and drifts were obtained and tabulated in Table 4. The load increments, which were described above, were applied to the specimens using a cyclic loading protocol, as shown in Figure 15. 
Table 4 - Cyclic displacement histories of specimens

\begin{tabular}{|c|c|c|c|c|c|c|}
\hline $\begin{array}{l}\text { Displacement } \\
\text { Steps }\end{array}$ & $\begin{array}{c}\text { Number } \\
\text { of } \\
\text { Cycles }\end{array}$ & $\begin{array}{c}\text { Cumulative } \\
\text { Num. of } \\
\text { Cycles }\end{array}$ & $\begin{array}{c}\text { Relative Disp. } \\
\text { Ratio to } \delta_{y} \\
\left(\Delta / \delta_{y}\right)\end{array}$ & $\begin{array}{c}\text { Relative } \\
\text { Disp. } \\
{[\mathrm{mm}]}\end{array}$ & $\begin{array}{l}\text { Top Disp. } \\
\text { [mm] }\end{array}$ & $\begin{array}{l}\text { Drift } \\
(\%)\end{array}$ \\
\hline Specimen BF & - & - & - & - & - & - \\
\hline 1 & 1 & 1 & 0.34 & 1.71 & 1.95 & 0.13 \\
\hline 2 & 1 & 2 & 0.67 & 3.29 & 4.03 & 0.24 \\
\hline 3 & 1 & 3 & 1 & 4.81 & 6.02 & 0.35 \\
\hline 4 & 1 & 4 & 2 & 9.29 & 12.03 & 0.68 \\
\hline 5 & 1 & 5 & 3 & 13.74 & 18.00 & 1.01 \\
\hline 6 & 1 & 6 & 4 & 17.68 & 23.46 & 1.30 \\
\hline 7 & 1 & 7 & 5 & 21.71 & 28.97 & 1.60 \\
\hline 8 & 1 & 8 & 6 & 26.13 & 34.91 & 1.92 \\
\hline 9 & 1 & 9 & 7 & 30.45 & 40.84 & 2.24 \\
\hline Specimen SP1 & - & - & - & - & - & - \\
\hline 1 & 3 & 3 & 0.34 & 1.52 & 2.17 & 0.11 \\
\hline 2 & 3 & 6 & 0.67 & 2.66 & 3.80 & 0.20 \\
\hline 3 & 3 & 9 & 1 & 4.35 & 6.22 & 0.32 \\
\hline 4 & 3 & 12 & 2 & 8.50 & 12.14 & 0.62 \\
\hline 5 & 3 & 15 & 3 & 12.61 & 18.01 & 0.93 \\
\hline 6 & 3 & 18 & 4 & 16.53 & 23.62 & 1.22 \\
\hline 7 & 3 & 21 & 5 & 21.36 & 30.51 & 1.57 \\
\hline 8 & 3 & 24 & 6 & 24.83 & 35.47 & 1.83 \\
\hline 9 & 3 & 27 & 7 & 28.77 & 41.10 & 2.12 \\
\hline 10 & 3 & 30 & 8 & 32.25 & 46.08 & 2.37 \\
\hline 11 & 3 & 33 & 9 & 36.88 & 52.69 & 2.71 \\
\hline 12 & 2 & 35 & 10 & 42.11 & 60.16 & 3.10 \\
\hline Specimen TL & - & - & - & - & - & - \\
\hline 1 & 3 & 3 & 0.34 & 1.45 & 1.99 & 0.11 \\
\hline 2 & 3 & 6 & 0.67 & 2.94 & 4.03 & 0.22 \\
\hline 3 & 3 & 9 & 1 & 4.41 & 6.04 & 0.32 \\
\hline 4 & 3 & 12 & 2 & 8.78 & 12.03 & 0.65 \\
\hline 5 & 3 & 15 & 3 & 13.19 & 18.07 & 0.97 \\
\hline 6 & 3 & 18 & 4 & 17.58 & 24.08 & 1.29 \\
\hline 7 & 3 & 21 & 5 & 21.99 & 30.13 & 1.62 \\
\hline 8 & 3 & 24 & 6 & 26.28 & 36.00 & 1.93 \\
\hline 9 & 3 & 27 & 7 & 30.90 & 42.33 & 2.27 \\
\hline 10 & 3 & 30 & 8 & 35.15 & 48.15 & 2.58 \\
\hline 11 & 3 & 33 & 9 & 39.36 & 53.92 & 2.89 \\
\hline 12 & 3 & 36 & 10 & 43.58 & 59.70 & 3.20 \\
\hline 13 & 3 & 39 & 11 & 48.07 & 65.84 & 3.53 \\
\hline 14 & 3 & 42 & 12 & 53.68 & 73.54 & 3.95 \\
\hline 15 & 3 & 45 & 13 & 56.95 & 78.01 & 4.19 \\
\hline
\end{tabular}

Note: Cyclic displacement histories of specimens SP2 and CLA are similar to specimen SP1 


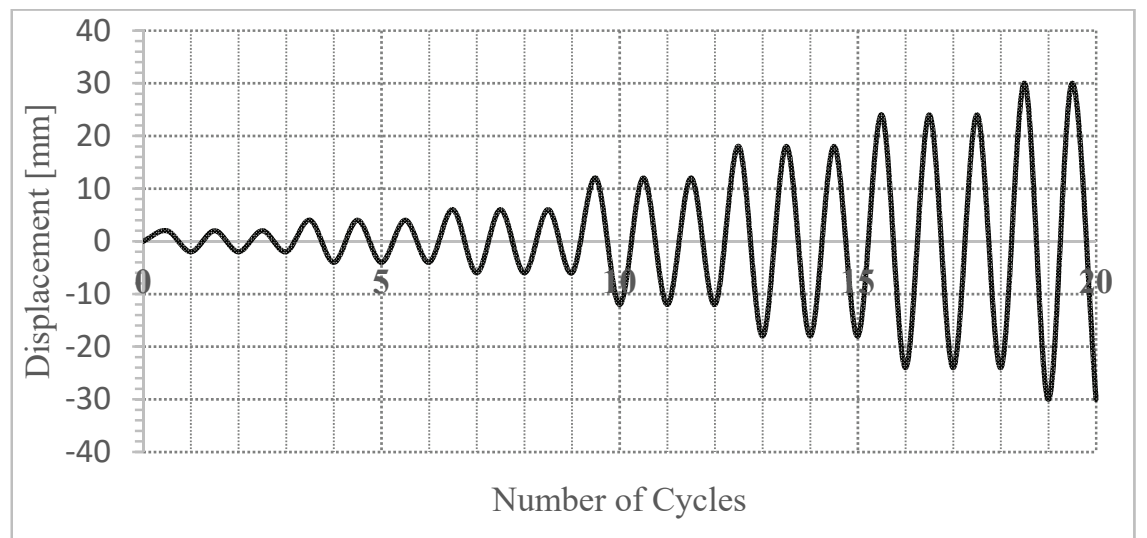

Figure 15 - Cyclic loading in accordance with the ATC 24 (1992) Protocol

\subsection{BF Bare Frame Specimen}

The cyclic hysteresis curves for the BF bare frame specimen are given in Figure 16, compared with the calibrated curve of the FEM. The frame showed elastic behavior during the first cycle, and plastic behavior started from the second cycle onward, which had a drift of $0.24 \%$. The initial stiffness of the frame was found to be $2.501 \mathrm{kN} / \mathrm{mm}$. When the drift was increased to $\pm 1 \delta_{y}(0.35 \%$ drift $)$, the cyclical curve covered a wider area than the previous cycles. At $0.68 \%$ drift, the beam web in the beam-to-column connections started to deform at bolt holes, giving rise to the yield marks shown in Figure 17.

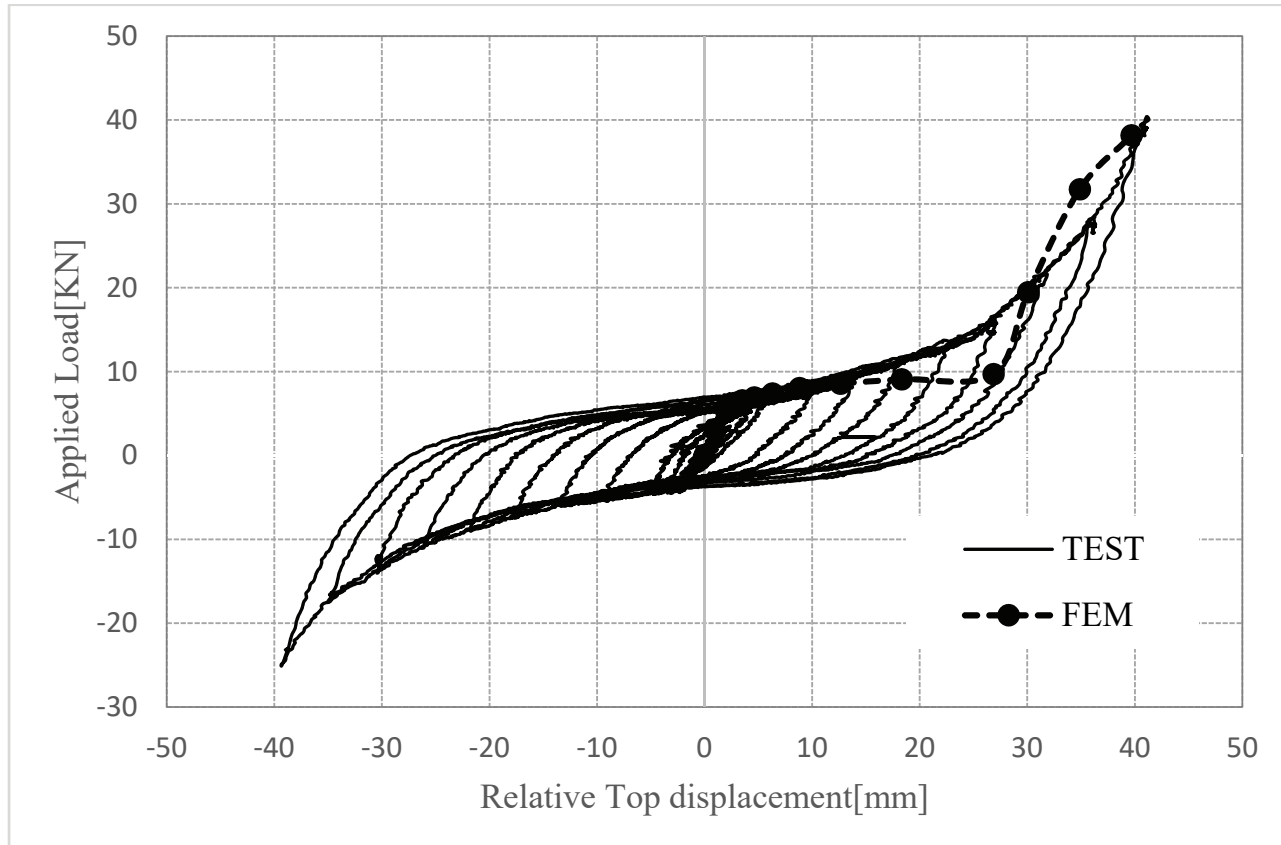

Figure 16 - Hysteresis loops and finite element analysis curve of Specimen BF 
From $-2 \delta_{y}$ and $+3 \delta_{y}$ displacements onward, the beam flanges in the beam-to-column connection started to transfer the moment while in contact with the column, as shown in Figure 18, resulting gradual and significant increase in the force. Figure 19 shows the envelope curves for the first four displacement cycles in the push direction and the first five displacement cycles in the pull direction. With regards to the situation in which the beam flanges did not come into contact with the column, the yield load of the bare frame was measured to be between $10 \mathrm{kN}$ to $15 \mathrm{kN}$. After $7 \delta_{y}$ and $2.24 \%$ drift level, the connection became fully plastic, but the load continued to increase because of contact. The experiment was ended after identifying the yield load of the connection as $10 \mathrm{kN}$ to $15 \mathrm{kN}$. The difference between push and pull load levels at similar displacements are due possible settling of bolts within their tolerance area, and also, small movements along transverse axis despite the rigidly-mounted out-of-plane frame to prevent such movements. No deformation was observed in the specimen other than yielding of the connections.

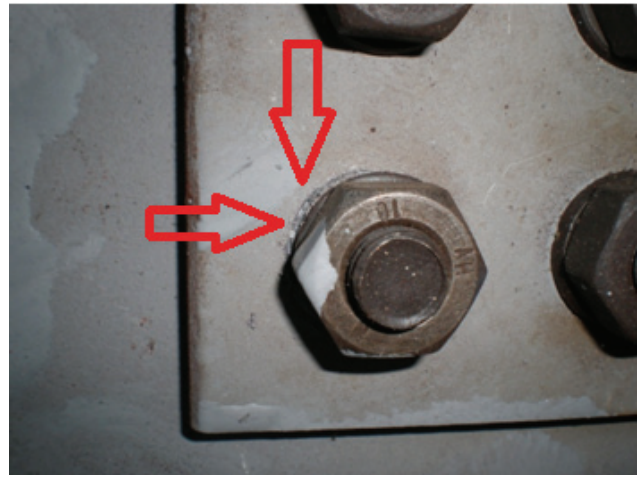

Figure 17 - Crushing of the connection on the web of the beam

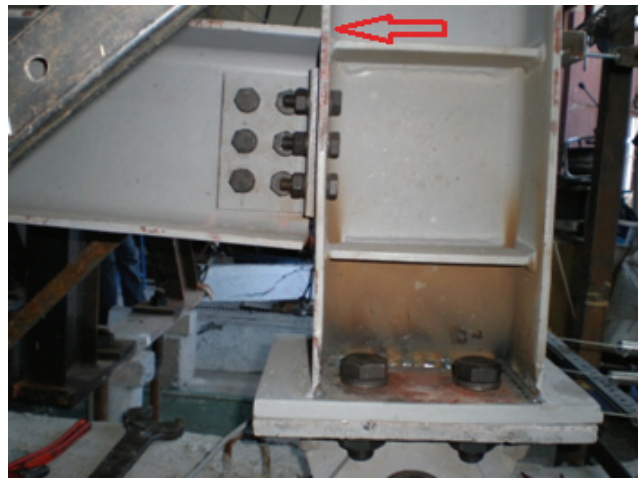

Figure 18 - Beam flange in the connection coming into contact with the column

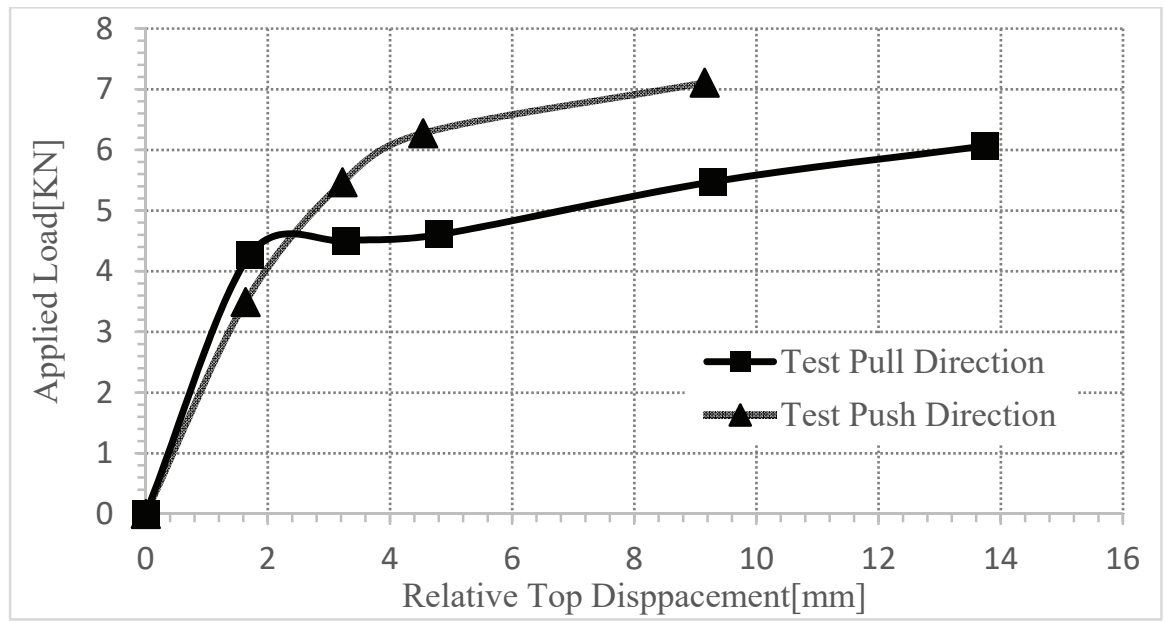

Figure 19 - Load displacement curves showing the effect of the nominally-pinned beamto-column connection of the bare frame $(B F)$ specimen 


\subsection{SP1 and SP2 Sandwich Panel Shear Wall Specimens}

Specimens SP1 and SP2 had similar characteristics and showed similar behavior. Thus, only the SP1 specimen is discussed in this subsection. The cyclic hysteresis curve of specimen SP1 is given in Figure 20. The specimen displayed an elastic behavior during the first nine cycles, at which point the light corrugated plates of the sandwich panel started flattening and buckling. When the specimen was loaded to $+2 \delta_{y}(0.62 \% \mathrm{drift})$, the post-elastic behavior was clearly visible on the graph. This drift could be referred to as the yield drift, and a base shear of $152.35 \mathrm{kN}$ was measured at this drift level. An approximately $5 \mathrm{~mm}$-wide buckling formed on both sides of the plate, in the form of a tension strip. At this point, the steel plates on the front and rear faces of the sandwich panel separated from the polyurethane infill, and became

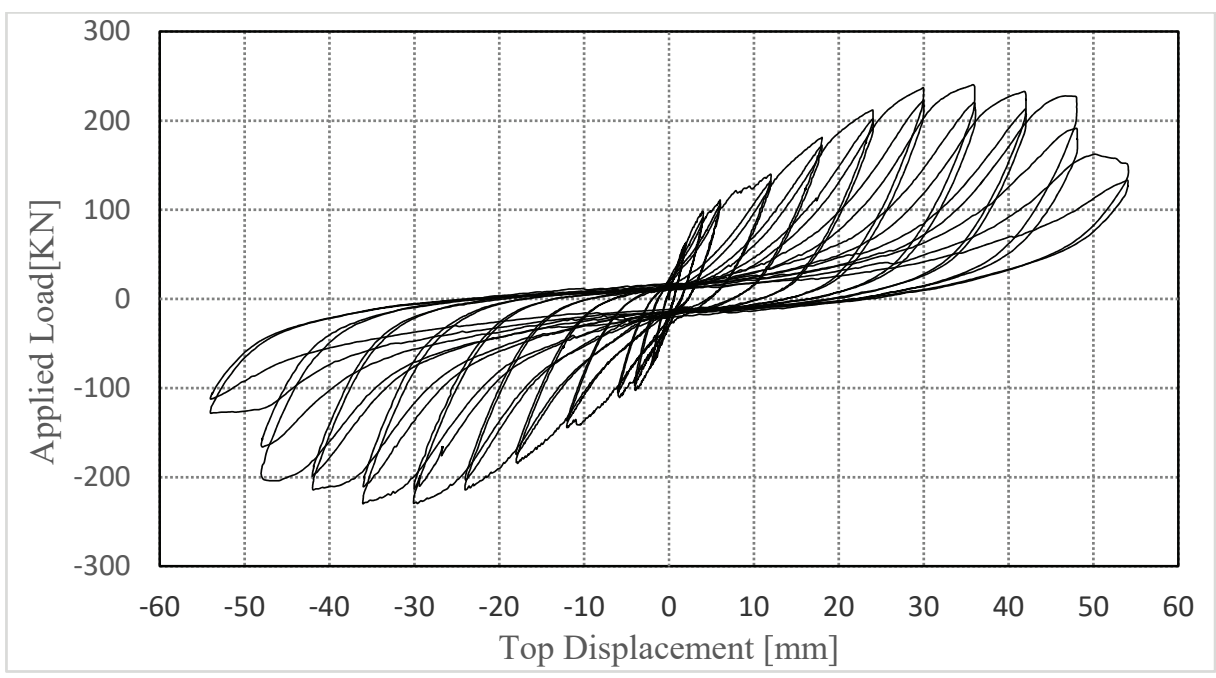

Figure 20 - Hysteresis loops of Specimen SP1

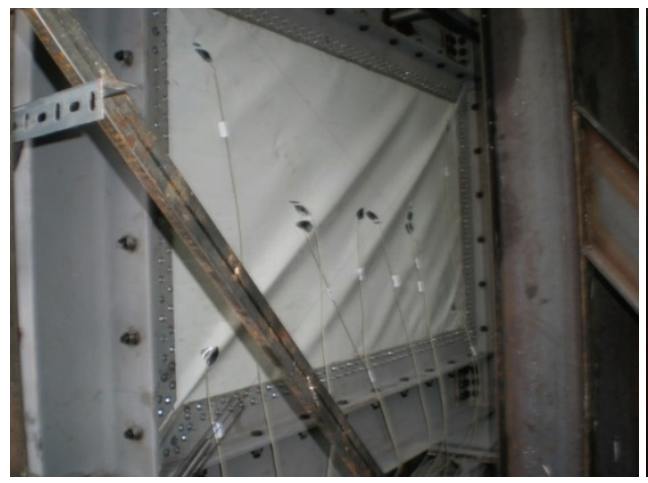

Figure 21 - Overview of the SP1specimen at $+4 \delta_{y}$ displacement step

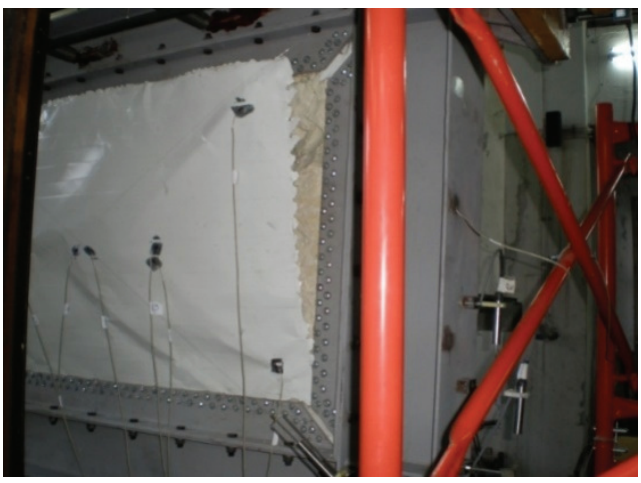

Figure 22 - SP1 Specimen, Plate was torn and completely separated from panel at $9 \delta_{y}$ 
two separate steel plates. Buckling was observed during $+4 \delta_{y}(1.22 \%$ drift $)$ as shown in Figure 21, where screw holes of the infill-plate to the fish-plate connection were crushed. During the second cycles of loading, the load was observed to decrease by $5 \%-15 \%$. For the next four displacement steps, the load values were close to each other, but the buckling wave size increased significantly. During the first cycle at $+7 \delta_{y}(2.12 \%$ drift $)$, a base shear of $249.75 \mathrm{kN}$ was measured, representing the highest maximum load value in this experiment. Out-of-plane buckling in the form of a plastic elongation of the plates, exceeded $50 \mathrm{~mm}$. At $+9 \delta_{y}(2.71 \% \mathrm{drift})$, the lateral load decreased to $156.30 \mathrm{kN}$, corresponding to $63 \%$ of the maximum load. As the connections of the plates were torn apart from their connections and were no longer usable (Figure 22-23), and no more load increment was observed at this point. Thus, the experiment was ended. The experimental specimen displayed a very ductile behavior during all cyclic loading cycles.

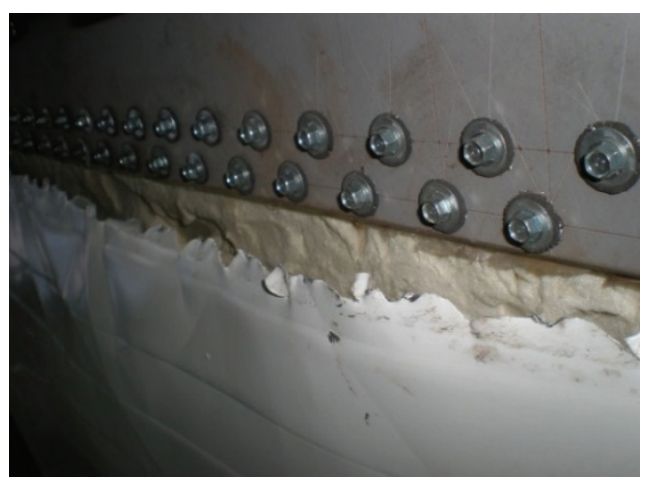

(a)

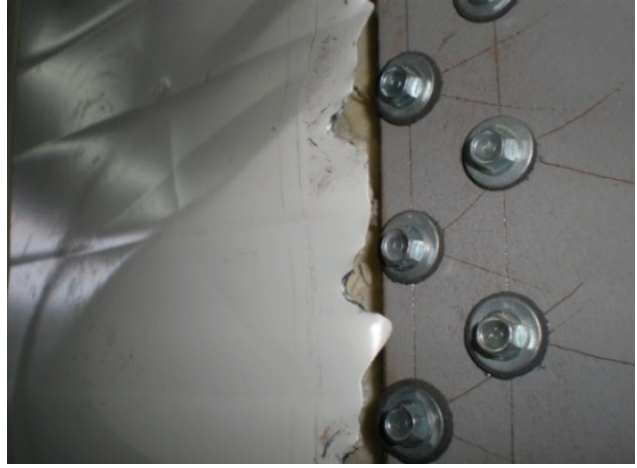

(b)

Figure 23 - SP1 Specimen 9 $\delta_{y}$; Plate crushed and torn around the screws at the plate-toframe connection; (a) front, (b) rear

\subsection{Specimen CLA with Two Separate Plates}

The cyclic behavior of the specimen is given in Figure 24. As the plates were thin and the polyurethane material was removed, the plate was unable to remain flat prior to loading. As a result, from the first cycles onward, tension fields formed in consequent displacements and the load values were obtained much less than prior test specimens (SP1 and SP2). A lateral load value of $104.61 \mathrm{kN}$ was obtained at $+2 \delta_{y}(0.57 \%$ drift $)$, and buckling fields formed on both sides of the plate. Compared to specimen SP1, the polyurethane material in the sandwich panel was observed to create a compression zone within the frame and increased the shear stiffness of the frame, in the first cycles up to $+4 \delta_{y}$. From this point onward, the CLA specimen behaved in a similar manner to the sandwich panel specimen as the polyurethane material in the SP1 specimen was completely crushed. The overview of the specimen at $-7 \delta_{y}$ $\left(2.07 \%\right.$ drift) is given in Figure 25, showing 20 to $30 \mathrm{~mm}$ tearing with a close to $45^{\circ}$ angle, perpendicular from the screw holes on the lower side of the plate-to-frame connection to the tension field (Figure 26). A maximum lateral load of $263.04 \mathrm{kN}$ was obtained during the first cycle at $+8 \delta_{y}(2.37 \%$ drift $)$. At $+9 \delta_{y}(2.66 \%)$, the load remained stable in the push direction, but decreased by $11 \%$ in the pull direction, which was compatible with the larger size of the 
tearing on the left-hand side of the specimen compared to those on the right-hand side. On the front side, a $60 \mathrm{~mm}$-long tearing formed at the plate connections. The out-of-plane buckling wave lengths of the plates exceeded $60 \mathrm{~mm}$. In the third cycle of the $-10 \delta_{y}(2.96 \%$ drift), the load decreased to $139.38 \mathrm{kN}$, representing $62 \%$ of the previous value, and large deformations were observed on the plates and in plate-to-frame connections, at which point the experiment was ended. Two or three tension fields were formed in the first cycles, but during later cycles, seven more noticeable tension fields were formed. In the last displacement step, the infill plate on the rear was completely torn from the net cross-section area (Figure 27).

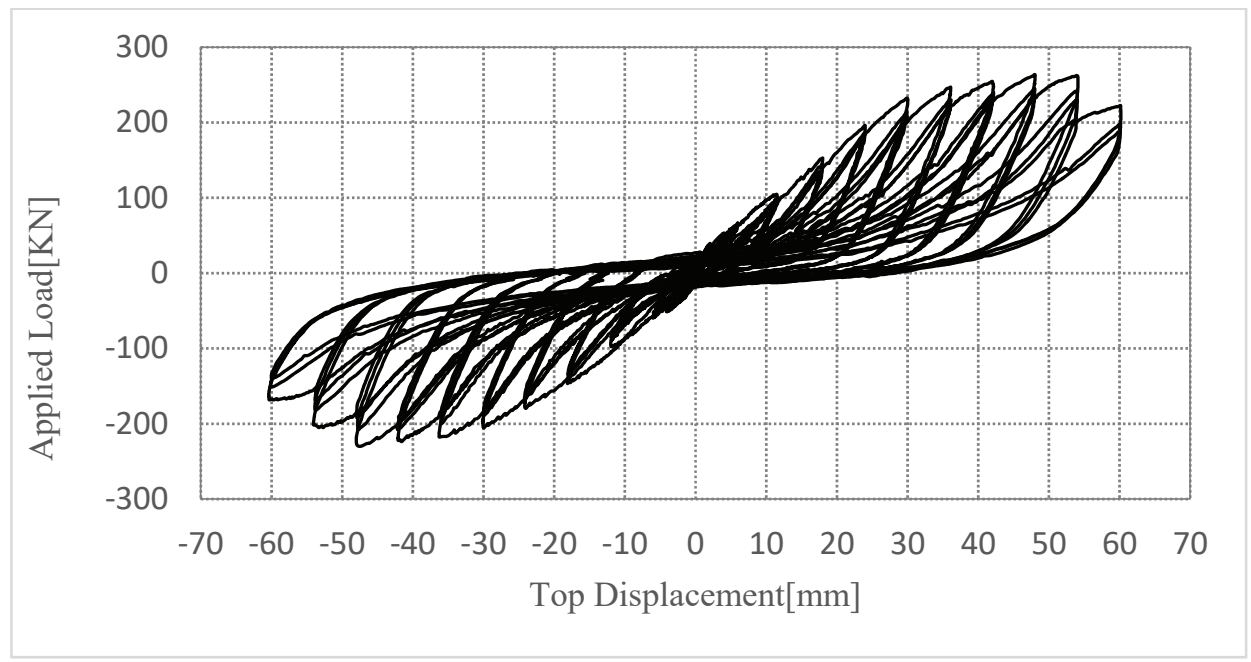

Figure 24 - Hysteresis loops of Specimen CLA

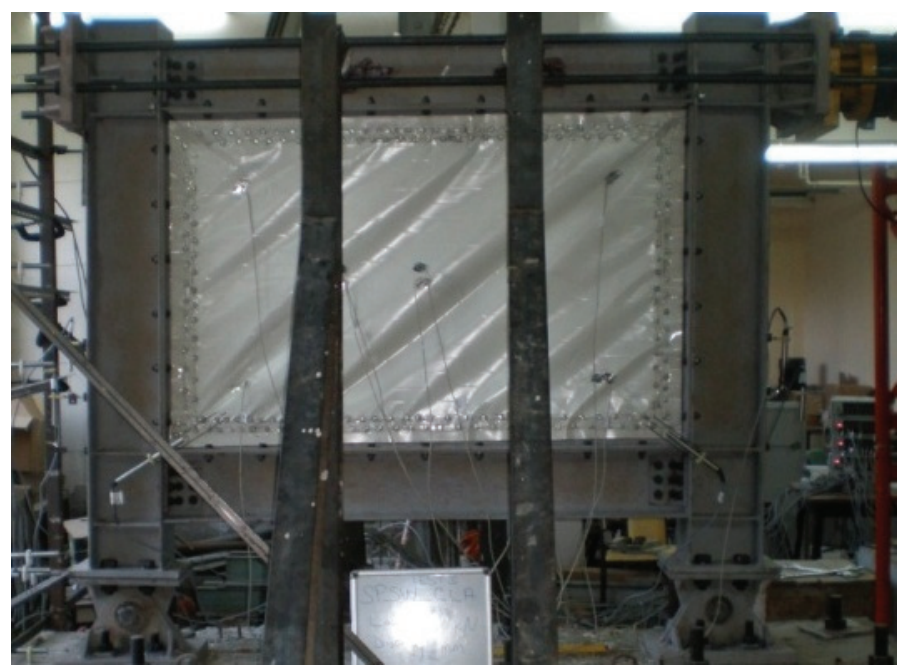

Figure 25 - Overview of the specimen at the $-7 \delta_{y}(42.00 \mathrm{~mm})$ displacement step. 


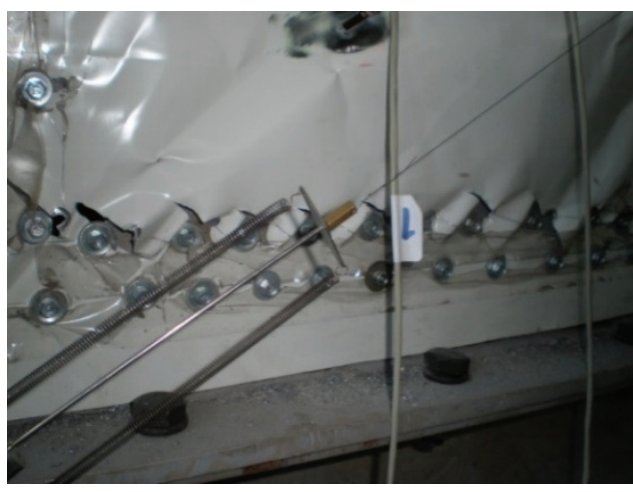

Figure 26 - $7 \delta_{y}$; front side plate-to-frame connections on the left, torn from the screw edges

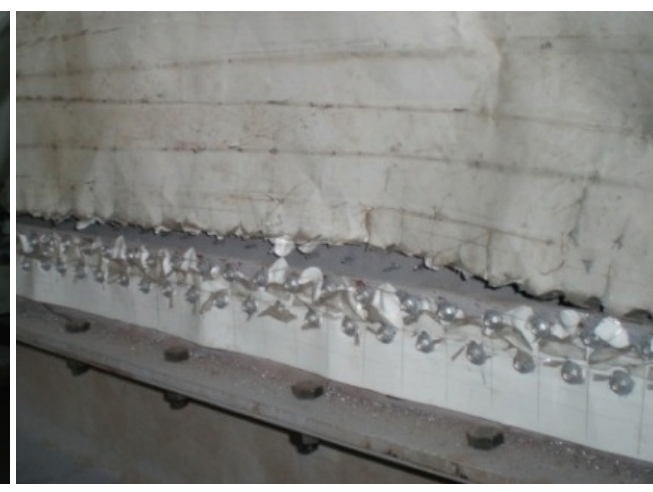

Figure 27 - 10 $\delta_{y}$; rear side plate-to-frame connections, lower edge, torn from the screw edges

\subsection{Specimen TL with a Single Plate}

The cyclic behavior of this specimen is given in Figure 28. Since the infill plate was thick, the initial out-of-plane deformation became smaller and the specimen was observed to be more stable under the applied loading. Thus, almost similar load levels were recorded in the push and pull directions. Linear elastic behavior was observed up to $+2 \delta_{y}(0.65 \% \mathrm{drift})$ and buckling marks with a height of $5 \mathrm{~mm}$ were formed. At $+5 \delta_{y}(1.62 \%$ drift), a base shear of $253.19 \mathrm{kN}$ was obtained. This value was closer to the maximum load values of the other specimens, and was obtained at a lower displacement value and with an insignificant nonlinear deformation.

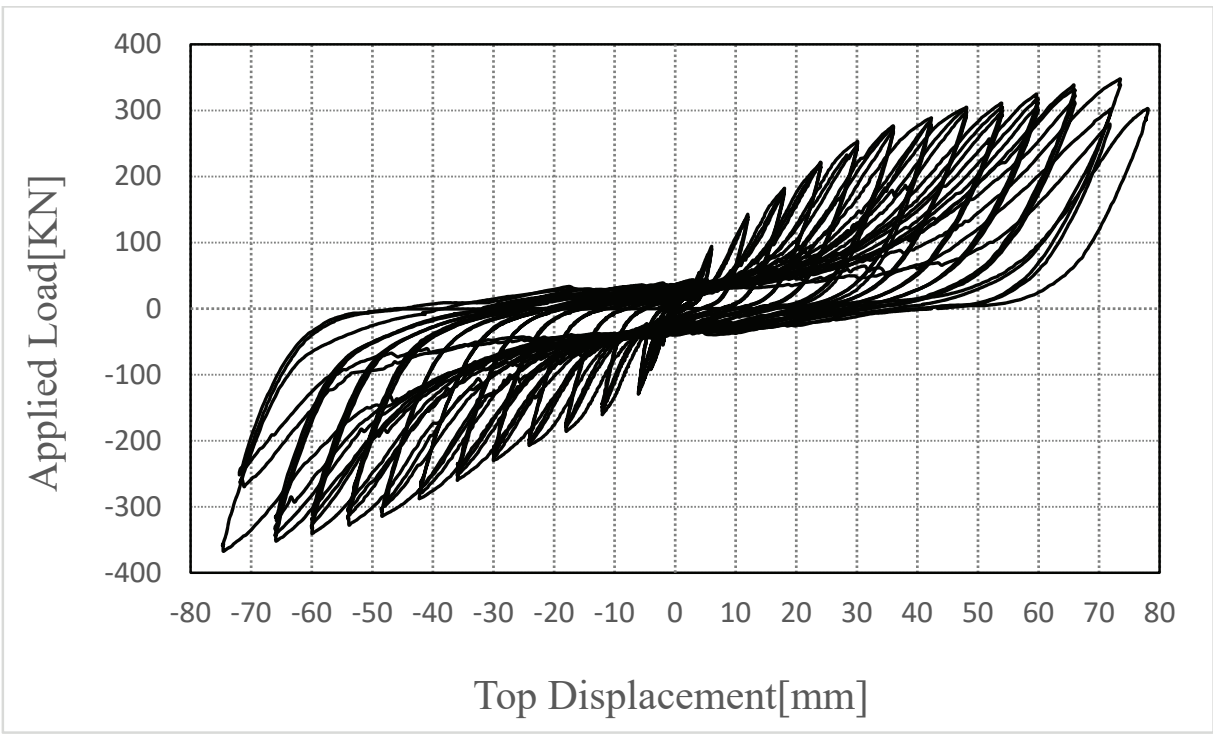

Figure 28 - Hysteresis loops of Specimen TL 
During the second cycles of loading, a decrease of $1 \%$ to $3 \%$ was observed at all steps, followed by a decline close to $5 \%$ during the third cycle. This showed that there was less plastic deformation as the plate became thicker. At $+11 \delta_{y}(3.53 \%$ drift $)$, tearing that formed during the previous displacement level became much larger, forming a $40 \mathrm{~mm}$-long tearing with an angle of almost $45^{\circ}$, while the load continued to increase (Figure 29). At $+12 \delta_{y}$ $(3.95 \%$ drift), base shears of $347.41 \mathrm{kN}$ in the push direction, and $367.52 \mathrm{kN}$ in the pull direction were recorded, representing the maximum load for this specimen. No tearing were formed in the net area of the plate connection screws, and with the repeated buckling of the plate, the tearing to the corners of the plates with an angle of about $45^{\circ}$ reached a length of $150 \mathrm{~mm}$ (Figure 30 ). The overview of the specimen in this displacement step, for the pull direction, is given in Figure 31.

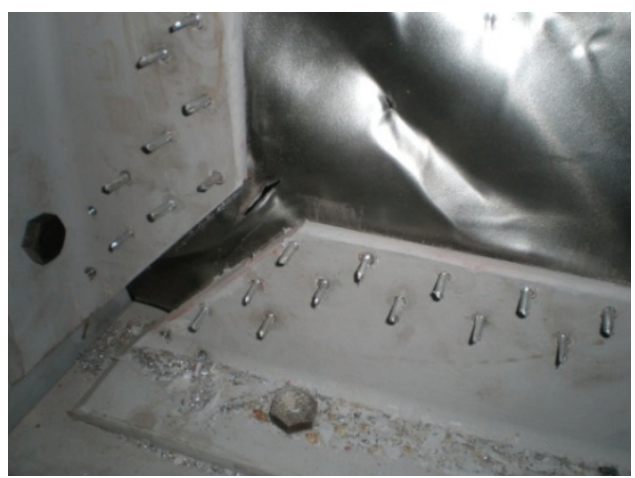

Figure 29 - $40 \mathrm{~mm}$ tear on the lower left corner of the rear side of Specimen $T L$, in displacement step $+11 \delta_{y}(65.84 \mathrm{~mm})$

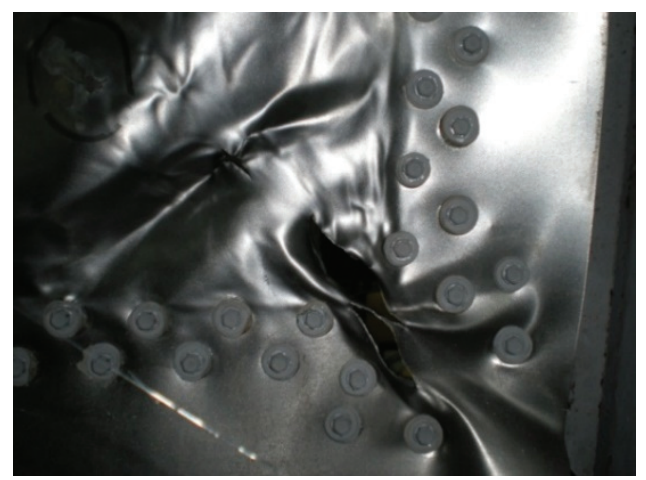

Figure - 30 Tears formed to the lower right corner of Specimen TL, on plate-to-frame connections, in the $+13 \delta_{y}(78.01 \mathrm{~mm})$

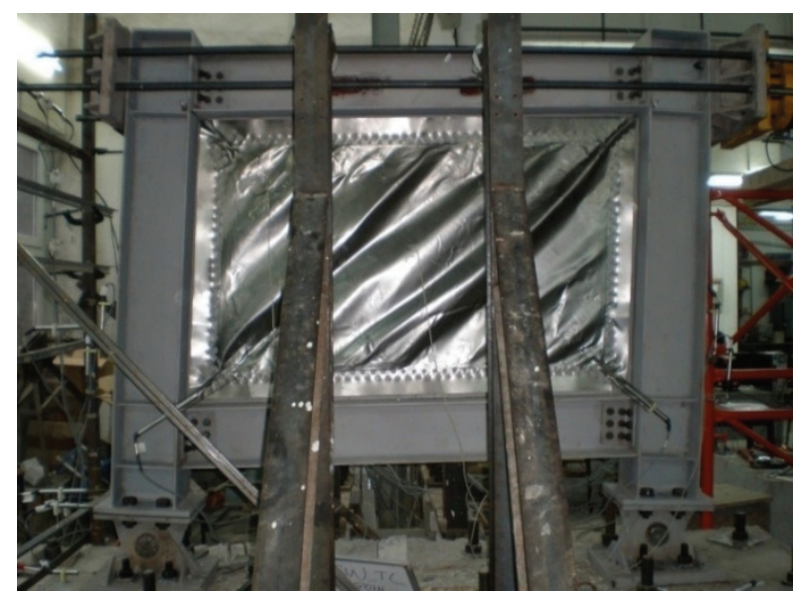

Figure 31 - Overview of the front side of the specimen $T L$ at the $-12 \delta_{y}(73.54 \mathrm{~mm})$ displacement step. 
During the first half cycle of the $43^{\text {rd }}$ cycle, $+13 \delta_{y}(4.19 \%$ drift $)$, the load value for a half cycle decreased to $302.90 \mathrm{kN}$. The setup to prevent out-of-plane movement of the specimen rubbed against the beam web, preventing loading, and there was a decrease in the pull direction to $68 \%$ of the maximum load capacity due to the tearing that formed on the corners. Thus, the experiment was ended at this stage, given the potential danger.

\section{COMPARISON OF RESULTS AND DISCUSSION}

The load and displacement relationships obtained from the experiments, as well as the maximum load capacity, stiffness and the amount of dissipated energy calculated on the basis of experimental results, were compared to evaluate the relative strengths and weaknesses of the specimens. Comparative load and displacement curves obtained from the experiments are given in Figure 32. Table 5 lists the load values recorded at various drift levels for all specimens. Table 6 presents the ratios of the maximum load values for all specimens to the maximum load values obtained for the bare frame. In addition, the bare frame lost its maximum load capacity from very early values onward and started to act like a pin connection. Table 7 was created to allow a comparison with Specimen SP2, which had the lowest maximum load capacity. This shows that the maximum load capacity of the singleplate specimen TL is about $45 \%$ higher than the other specimens of thin plates with two sides, whereas sandwich panels, with appropriate connections, resulted a very high lateral load resisting capacity compared to the bare frame, and it can therefore be used as an efficient lateral load resisting system.

Table 5 - Load Values Classified by Drift (kN)

\begin{tabular}{cccccc}
\hline Drift [\%] & BF & SP1 & CLA & TL & SP2 \\
\hline 0.25 & 4.51 & 116.04 & 60.37 & 67.02 & 107.78 \\
0.50 & 4.99 & 142.72 & 95.41 & 118.89 & 131.58 \\
0.75 & 5.59 & 164.57 & 132.00 & 153.09 & 161.68 \\
1.00 & 6.05 & 189.84 & 168.98 & 185.64 & 192.12 \\
1.25 & 7.23 & 215.98 & 204.28 & 215.66 & 216.61 \\
1.50 & 8.53 & 234.57 & 233.55 & 241.48 & 236.95 \\
1.75 & 9.99 & 238.08 & 245.24 & 263.10 & 239.59 \\
2.00 & 11.79 & 244.82 & 252.69 & 279.06 & 240.02 \\
2.25 & 14.26 & 245.74 & 259.72 & 287.75 & - \\
2.50 & - & - & 262.68 & 300.27 & - \\
3.00 & - & - & - & 315.65 & - \\
3.50 & - & - & - & 337.21 & - \\
4.00 & - & - & - & 344.67 & - \\
\hline
\end{tabular}


The initial stiffness values of the test specimens were calculated from the pre-yield points of the cyclic graph envelope curves recorded during loading. To examine the effect of adding an infill plate, and the use of different types of infill plates, Table 8 shows the mean stiffness values for the push and pull directions, and compares their ratios to the stiffness value of the bare frame specimen.

Table 6 - Maximum load capacities of specimens in the push direction, and their ratios to the bare frame

\begin{tabular}{ccccc}
\hline Test No. & Specimen Mark & Maximum Load $[\mathbf{k N}]$ & Ratio Definition & Ratio \\
\hline $\mathbf{1}$ & $\mathrm{BF}$ & 8.89 & $\mathrm{BF} / \mathrm{BF}$ & 1.0 \\
$\mathbf{2}$ & $\mathrm{SP} 1$ & 249.75 & $\mathrm{SP} 1 / \mathrm{BF}$ & 28.1 \\
$\mathbf{3}$ & $\mathrm{CLA}$ & 263.04 & $\mathrm{CLA} / \mathrm{BF}$ & 29.6 \\
$\mathbf{4}$ & $\mathrm{TL}$ & 347.42 & $\mathrm{TL} / \mathrm{BF}$ & 39.1 \\
$\mathbf{5}$ & $\mathrm{SP} 2$ & 240.22 & $\mathrm{SP} 2 / \mathrm{BF}$ & 27.0 \\
\hline
\end{tabular}

Table 7 - Comparison of the Maximum Load Capacities of the Steel Plate Shear Walls

\begin{tabular}{ccccc}
\hline Test No. & Specimen Mark & Maximum Load $[\mathbf{k N}]$ & Ratio Definition & Ratio \\
\hline $\mathbf{2}$ & SP1 & 249.75 & SP1/SP2 & 1.04 \\
$\mathbf{3}$ & CLA & 263.04 & CLA/SP2 & 1.10 \\
$\mathbf{4}$ & TL & 347.42 & TL/SP2 & 1.45 \\
$\mathbf{5}$ & SP2 & 240.22 & SP2/SP2 & 1.00 \\
\hline
\end{tabular}

Table 8 - Comparing Stiffness Values of the Experimental Specimens

\begin{tabular}{ccccc}
\hline Test No. & Specimen Mark & Initial Stiffness $[\mathbf{K N} / \mathbf{m m}]$ & Ratio Definition & Ratio \\
\hline $\mathbf{1}$ & $\mathrm{BF}$ & 2.32 & $\mathrm{BF} / \mathrm{BF}$ & 1.00 \\
$\mathbf{2}$ & $\mathrm{SP} 1$ & 48.76 & $\mathrm{SP} 1 / \mathrm{BF}$ & 21.02 \\
$\mathbf{3}$ & $\mathrm{CLA}$ & 27.91 & $\mathrm{CLA} / \mathrm{BF}$ & 12.03 \\
$\mathbf{4}$ & $\mathrm{TL}$ & 32.59 & $\mathrm{TL} / \mathrm{BF}$ & 14.05 \\
$\mathbf{5}$ & $\mathrm{SP} 2$ & 52.40 & $\mathrm{SP} 2 / \mathrm{BF}$ & 22.59 \\
\hline
\end{tabular}

Specimens SP1 and SP2 had significantly higher initial stiffness values than the other specimens. As the steel plates on both sides of the $100 \mathrm{~mm}$-thick sandwich panel turned into tension strips and the polyurethane material between $0.5 \mathrm{~mm}$ thin steel plates was compressed and started to act as a compression zone, an increase in stiffness was observed in the first cycles. The sandwich panel specimens were observed to have average stiffness values that were $65 \%$ higher than those of other steel plate shear wall specimens. The infill plate contributed to stiffness in all specimens, while the use of sandwich panels provides additional initial stiffness, resulting in behavior similar to the composite plate shear walls during early 
cycles. The steel plate shear wall and sandwich panel shear wall specimens had initial stiffness values that are 12 to 22 times, respectively, that of the initial stiffness of the bare frame with nominally-pinned beam-to-column connections. Even though two-sided specimens had the same total plate thickness, crushing and tearing of cross-sections were observed around the infill plate-to-fish plate connection holes of the thin plates with smaller displacements. Until the end of the experiment, no net cross-section area tearing was formed around the screw holes of the single-plate specimen TL, which had a thickness of $1.0 \mathrm{~mm}$, matching the total thickness of the plates on both sides of the sandwich panel. The yielding of the plates took the form of tearing to the plate corners as a result of repeated loading. This difference between the two-sided specimen and the single-plate specimen, with matching total plate thicknesses, could be attributed to the lack of uniform distribution of the load in practice, even though in theory the load should have been distributed equally.

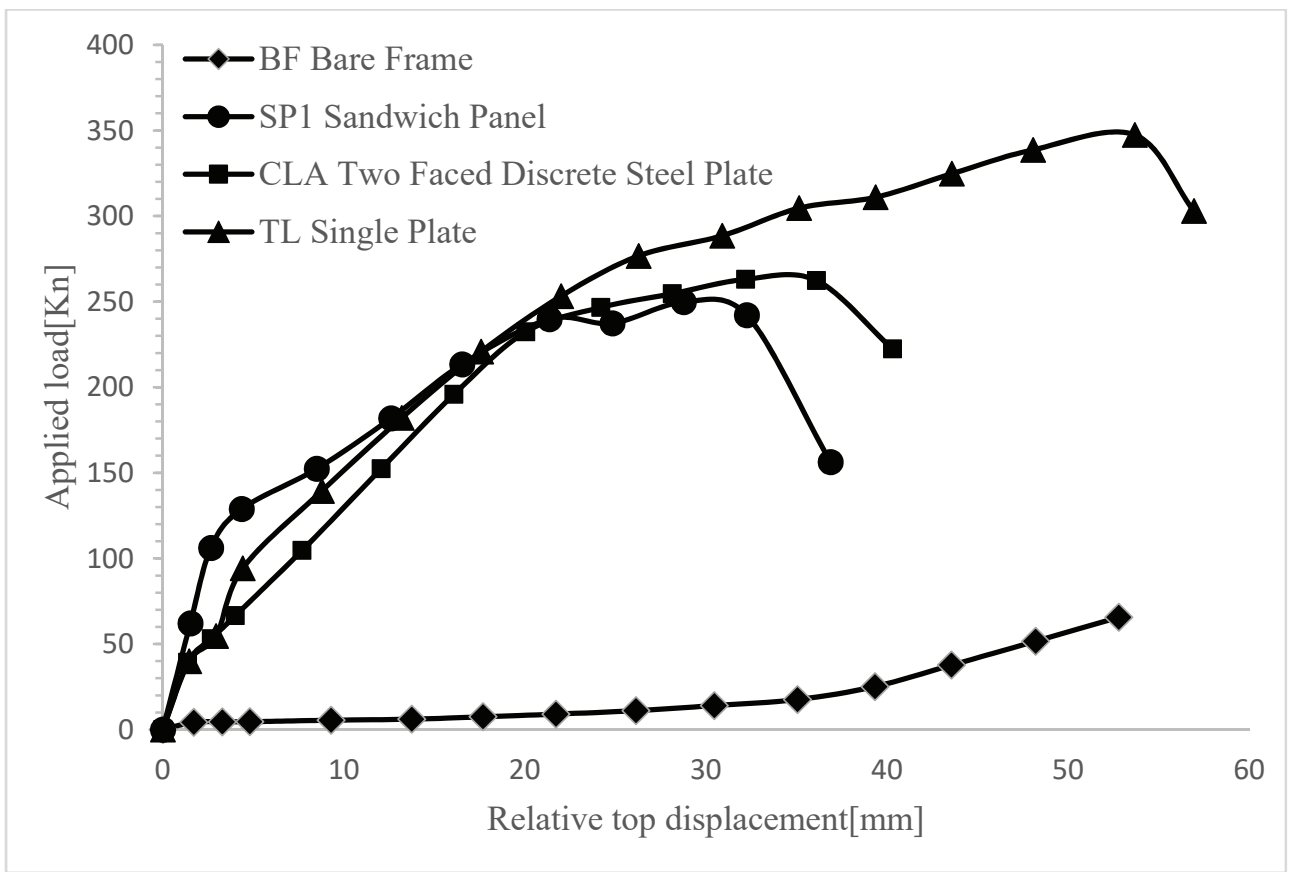

Figure 32 - Comparing the experimental load-displacement curves of specimens

Energy dissipation amounts were used to compare and evaluate the test results. Dissipated energy was calculated as the area encompassed by the load displacement curve for every cycle. At $2.5 \%$ drift, Specimen SP1 dissipated an energy 15 times more than that of the bare frame, while Specimen CLA dissipated 18 times more energy and Specimen TL dissipated 19 times more energy. Based on drift ratios of each specimen, the cumulative energy amounts summed up over the first cycles are given in Figure 33. This shows that the sandwich panel used as an infill wall inside the frame dissipated a very high amount of energy, approximating the behavior of the steel plate shear wall specimen, and by simply making an appropriate connection, this method could turn the frame, with little additional cost, into a worthy lateral load resisting system. The sandwich panel shear wall that was designed by attaching the steel 
plates on both sides of the sandwich panel to the frame using screws was observed to display ductile behavior under cyclic loading, similar to the steel plate shear wall with a single plate. When the plate yields, it can be removed from the connecting structural elements and new infill plates can be installed easily, as shown in Figure 34. At the end of the test, round bolt holes took the shape of elliptical indicating ductile behavior. No excessive visible damage such as shearing or bending of bolts were observed. It is noteworthy to say that in case there is a need for replacement of panels, the angles should be removed and replaced with the new ones. The orientation angle of the tension field was observed to be $49^{\circ}$ in the sandwich panel specimens and $47^{\circ}$ in the single-plate specimen, and was calculated to be $46^{\circ}$ using Equation 1.

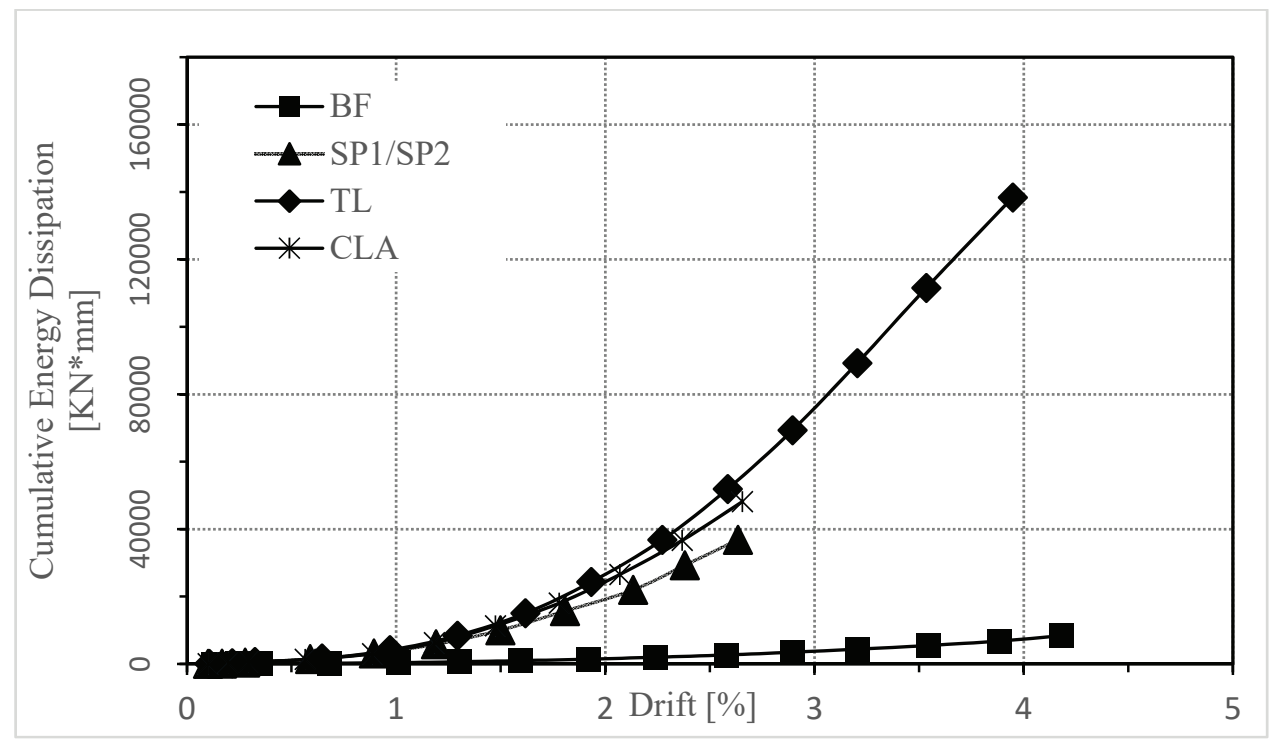

Figure 33 - Comparison of the cumulative energy amounts dissipated

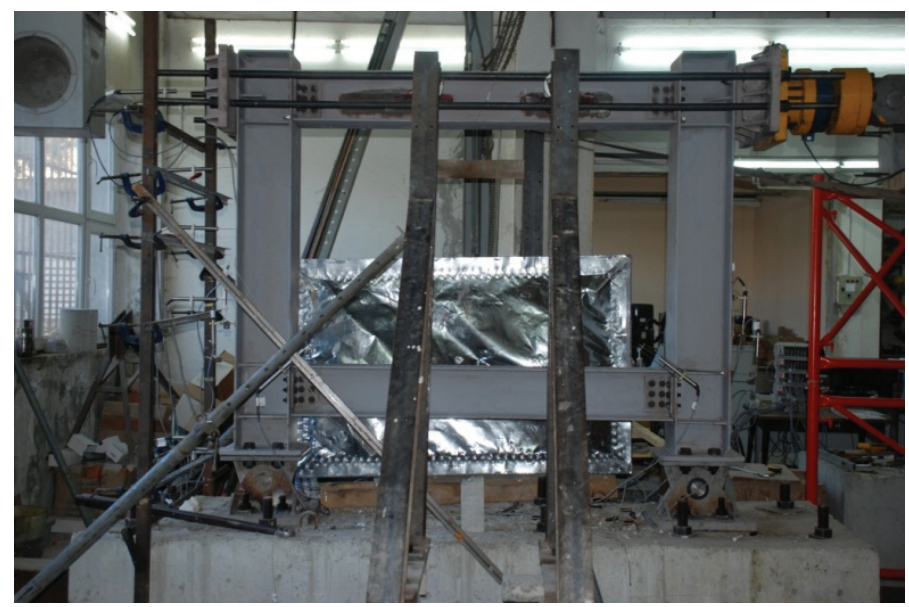

Figure 34 - When the plate yields, removing infill plates from the connecting structural elements can be easily performed 


\section{CONCLUSIONS}

This study aimed to increase the strength, stiffness and energy dissipation capacity of a bare frames by attaching sandwich panels used as partition walls with an appropriate connection design, and thus making them behave similar to steel plate shear walls. To this end, a bare frame specimen, two sandwich panel specimens, a specimen with the polyurethane material removed from sandwich panel, and a single-plate specimen of matching thickness were prepared. Quasi-static loads were applied following ATC 24 [29] guidelines.

To be able to observe the effect of the infill plate clearly, a nominally-pinned beam-to-column connection was preferred, in which the beam web is attached to the column with two angle brackets, which are used frequently in design of steel constructions. A nominally-pinned connection was preferred in order to focus on the behavior of the infill plates only.

The polyurethane material inside the steel plates in the form of sandwich panel behaved like a compression zone, resulting in a significant increase in stiffness in the first cycles, when compared to the other specimens. Also compared to the other specimens, the polyurethane material absorbs the buckling sound of the steel plates during the first cycles.

In order to achieve a ductile behavior, the aim was to make the plate yield, rather than tearing it at the connection region to the frame. The reason why single plate $(1.00 \mathrm{~mm})$ specimen's load and energy dissipation capacities were higher, compared to the two-faced $(0.5 \mathrm{~mm}+$ $0.5 \mathrm{~mm}$ ) plate specimen, was its thickness. While the SP1, SP2 and CLA specimens yielded or formed a mechanism due to tearing of plate around the screw connection region, the TL specimen dissipated energy under cyclic loading until the yielding load was attained.

The experimental results showed that a sandwich panel used as a partition wall inside a frame is able to dissipate a very high amount of energy, approximating the behavior of a steel plate shear wall specimen, contributing significantly to lateral load resistance and stiffness values, as long as it is attached to the frame with an appropriate connection design on both sides. This method can turn partition walls into a sound lateral load resisting system, with little additional cost. In addition, the light corrugated plate structure of the sandwich panels increases ductility.

The angles attaching the plate to the frame with bolts can be removed after significant damage after an earthquake. It is possible to conduct analyses using a strip model, as similar tension field formations were observed in both the steel plate and the sandwich panel shear wall specimens; however, further study is needed on the methods of analysis that would take the contribution of the polyurethane material into account.

Finally, specimens SP1 and SP2 were observed to be less effective than specimen TL, especially in terms of their dissipated energies.

\section{Acknowledgements}

The authors would like to thank to the staff of Boğazici University's Structural and Materials laboratories, where the experimental study was conducted. Also, special thanks go to Arcelor Mittal RZK for donating all the steel sections and Cağla Engineering for constructing specimens for the experimental study. Finally, authors would like to thank to Sakarya University Scientific Research Projects Unit for its financial support with the Project Number 2007-50-02-022. 


\section{References}

[1] Mimura, H. and Akiyama, H. (1977). "Load-deflection relationship of earthquake resistant steel shear walls with a developed diagonal tension field." Trans., Arch. Inst. Of Japan, Tokyo, Japan, 109-114.

[2] Agelidis, N. and Mansell, D. S. (1982). "Seismic steel plate cores in tall buildings." Civil Engineering Transactions of the Institution of Engineers, Australia, CE24 (1), 11 18.

[3] Rezai, M. (1999). "Seismic behavior of steel plate shear walls by shake table testing." PhD Thesis, University of British Columbia, Vancouver, Canada.

[4] Yamada, M. (1992). "Steel panel encased R.C. composite shear walls." Proceedings of the ASCE Engineering Foundation Conference on Composite Construction in Steel and Concrete II, pp. 899-912.

[5] Caccese, V., Elgaaly, M. and Chen, R. (1993). "Experimental study of thin steel-plate shear walls under cyclic loading." Journal of Structural Engineering, 119, 0573-0587.

[6] Sabouri-Ghomi, S. and Roberts, T. M. (1991). "Nonlinear dynamic analysis of thin steel plate shear walls." Computers \& Structures, 39, 121-127.

[7] Takahashi, Y., Takemoto, Y., Takeda, T. and Takagi, M. (1973). "Experimental study on thin steel shear walls and particular bracings under alternative horizontal load." IABSE Symposium, On Resistance and Ultimate Deformability of Structure Acted on by Well-Defined Repeated Loads, Lisbon, Portugal, 185-191.

[8] Timler, P. A. and Kulak, G. L. (1983). "Experimental study of steel plate shear walls." Structural Engineering Report, 114, University of Alberta, Edmonton, Alta, Canada.

[9] Tromposch, E. W. and Kulak, G. L. (1987). "Cyclic and static behavior of thin panel steel plate shear walls." Structural Engineering Report, 145, University of Alberta, Edmonton, Alta, Canada.

[10] Driver, R. (1997). "Seismic behavior of steel plate shear walls." PhD Thesis, University of Alberta, Edmonton, Canada.

[11] Behbahanifard, M. R. (2003). "Cyclic behavior of unstiffened steel plate shear walls." $\mathrm{PhD}$ Thesis, University of Alberta, Edmonton, Canada.

[12] Alinia, M.M. and Shirazi, R.S. (2009), "On the design of stiffeners in steel plate shear walls.” Journal of Constructional Steel Research 65 (2009) 2069-2077.

[13] Xue, M. and Lu, L. W. (1994). "Interaction of infilled steel shear wall panels with surrounding frame members.” Proc. Struct. Stability Res. Council Annu. Tech. Session, Bethlehem, Pa., 339-354.

[14] Purba, R. and Bruneau, M. (2015), "Experimental investigation of steel plate shear walls with in-span plastification along horizontal boundary elements." Engineering Structures, 97, 68-79.

[15] Formisano, A. and Lombardi, L. (2018). "Low yield metals and perforated steel shear walls for seismic protection of existing RC buildings." Cogent Engineering, 5(1), 1525813 . 
[16] Alavi, E. and Nateghi, F. (2013), "Experimental study on diagonally stiffened steel plate shear walls with central perforation." Journal of Constructional Steel Research 89, 9-20.

[17] Eom, T., Park, H., Lee, C., Kim, J. and Chang, I. (2009), "Behavior of Double Skin Composite Wall Subjected to In-Plane Cyclic Loading." Journal of Structural Engineering, 1239-1249.

[18] Aoyama, H. and Yamamoto, Y. (1984), "Aseismic strengthening of existing RC buildings by steel panel shear walls with rims." Transactions of the Japan Concrete Institute, 6: 733-740.

[19] Astaneh-Asl, A. and Zhao, Q. (2002). "Cyclic behavior of shear wall systems." Proceedings, Annual Stability Conference, Structural Stability Research Council, April, Seattle.

[20] Berman, J., Celik, O. C. and Bruneau, M. (2005). "Comparing hysteretic behavior of light-gauge steel plate shear walls and braced frames." Engineering Structures, 27, 475485 .

[21] Dey, S., Bhowmick, A.K. (2016), "Seismic performance of composite plate shear walls." Structures 6, 59-72.

[22] Vatansever, C. (2008). "Cyclic behavior of thin steel plate shear walls with semi-rigid beam-to-column connections." PhD Thesis, Istanbul Technical University, Institute of Science, Istanbul, Turkiye.

[23] Choi, I. and Park, H. (2009), "Steel plate shear walls with various infill plate designs." Journal of Structural Engineering, 0733-9445(2009)135:7(785).

[24] Vatansever, C. and Yardimci, N. (2011), "Experimental investigation of thin steel plate shear walls with different infill-to-boundary frame connections." Steel and Composite Structures, Vol. 11, No. 3, 251-271.

[25] Berman, J. and Bruneau, M. (2005). "Experimental investigation of light-gauge steel plate shear walls." Journal of Structural Engineering, 131 (2), 259-267.

[26] Vatansever C. and Berman J.W., (2015), "Analytical investigation of thin steel plate shear walls with screwed infill plate." Steel and Composite Structures, 19 (5), 1145 1165.

[27] Hibbit, Karlsson, Sorenson, Inc., (HKS), "ABAQUS/Standard Theory Manual." Student Edition 6.13. Pawtucket, R.I.

[28] SAP2000, "Structural Analysis Program, Computers and Structures." Inc., Berkeley, California, USA.

[29] ATC-24, (1992). "Guidelines for cyclic seismic testing of components of steel structures.” Applied Technology Council, California. 
